\title{
A Modified Customization Strategy in a Dual-Channel Supply Chain Model with Price-Sensitive Stochastic Demand and Distribution-Free Approach
}

\author{
Ruchi Chauhan, ${ }^{1}$ Varun Kumar, ${ }^{1}$ Tapas Kumar Jana, ${ }^{2}$ and Arunava Majumder $\mathbb{D}^{1}$ \\ ${ }^{1}$ Department of Mathematics, Lovely Professional University, Phagwara, Punjab 144411, India \\ ${ }^{2}$ Department of Mathematics, Ghatal Rabindra Satabarsiki Mahavidyalaya, Ghatal, West Bengal 721212, India \\ Correspondence should be addressed to Arunava Majumder; am.arunavamajumder@gmail.com
}

Received 13 May 2021; Revised 15 August 2021; Accepted 20 August 2021; Published 23 September 2021

Academic Editor: Vahid Kayvanfar

Copyright (c) 2021 Ruchi Chauhan et al. This is an open access article distributed under the Creative Commons Attribution License, which permits unrestricted use, distribution, and reproduction in any medium, provided the original work is properly cited.

\begin{abstract}
With the advancement of technology, many companies provide customization facilities to customers. This facility provides a vast variety to customers which enhances the level of customer satisfaction. This approach helps various technologically advanced companies to increase their profit. In this paper, a dual-channel supply chain model is developed with the aforementioned customization strategy with the target of increasing the profit of the firm. In dual-channel, the core or standard product is provided to the customer through a traditional retail channel, whereas the customized product is made available through the online channel. This article incorporates a modification in the existing dual-channel policy on the number of customers that switch between the offline and online channels. Moreover, a preassigned threshold value is also assumed which signifies the decrease in demand that takes place if the difference between the selling price of offline and online channels crosses a fixed specified threshold value. In addition to that, due to fluctuation and uncertainty of demand, both variability and randomness may occur simultaneously. Thus, the price-sensitive stochastic demand is considered to develop the dual-channel centralized supply chain model with customization. A max-min distribution-free approach is applied to deal with the randomness and variability of demand. The model is analyzed and validated with numerical experiments and graphical analysis. Consequently, the article concluded that it is better to adopt a dual-channel supply chain policy for better profitability than the traditional single-channel supply chain as this firm will be able to provide customized products to customers. Moreover, if the difference between the selling prices of the offline and online channels is greater than the preassigned threshold value, then the shifting of customers takes place depending upon the factor that which channel's selling is less in comparison to another.
\end{abstract}

\section{Introduction}

The growth of Internet has revolutionized the concept of supply chain management in a significant manner. Several statistical reports of various groups show that e-commerce has accelerated the economic situation of modern marketing environment. In 1985, Dell embraced the strategy of builtto-order computers on demand of customers. This approach provided Dell a sale of $\$ 70$ million in that year, and after five years of adopting the strategy, their revenue climbed to $\$ 500$ million. By the end of 2000, Dell's revenues had topped with an astounding of $\$ 25$ billion [1]. In this respect, current study compares the traditional retail channel with the online channel under customization strategy. Many manufacturers sell their standard products to the retailers through conventional retail channel and customized product directly to the customers according to their requirement. Therefore, in order to achieve a smooth supply chain flow companies, use dual-channel supply chain, [2-4] and [5].

Furthermore, the dual-channel supply chain model provides the customers with many options to choose either standard products from the retailer or customized products through online channel [6-8]. In addition to that, manufacturers are adopting e-commerce to compete with their 
opponents [9] and implementing green technology in the manufacturing industry for reduction of greenhouse gas emission $[10,11]$. The retailer's services and behavior greatly influence the choices and demand of the customer $[12,13]$. Many customers prefer online platform as it saves some amount of cost and time due to the direct interaction between the manufacturer and the customer under online environment [14]. Moreover, in the online channel, the customers are also provided with the feedback facility which ultimately helps the manufacturer to know their customer and improve their services accordingly [14].

Some well-known manufacturing and retailing industries such as Nike started producing the customized products on demand of customers through online channel. The traditional retail channel is also utilized to deliver the standard products without any customization $[15,16]$. A study reveals that around $42 \%$ of the top brands are catering the customers directly through online channel [17]. Priorly, with the acceptance of the online channel, it would create conflict between the manufacturer and the retailer as it would shrink the retailer's market share. However, studies have shown that whole sale prices reduce for product sold through the retailer and increase the profit of the firm with the establishment of online channel $[18,19]$. With the introduction of online channel along with offline channel, house needs to define markup margin accurately as it influences the wholesale prices.

This paper put up to the studies in several aspects which were unnoticed in the previous literature. The main contributions of this research lie under the consideration of threshold limit, unequal shifting of customers, multidelivery policy, uncertain demand, and controllable lead time in the dual-channel supply chain model with customization policy. Heretofore, researchers developed several dual-channel models but with equal number of customer shifting from the online to offline channel and vice versa. The concept of equal customer shifting between the channels may not be realistic as all customers, who are unwilling to purchase items from one channel, are not forced to shift to another one. Secondly, a preassigned threshold limit is considered in this article which was not assumed in previous research studies. The threshold limit is incorporated under the concept that a customer is only willing to change the mode of purchase if the selling price difference between the two channels crosses to a specified price limit. These two important modifications on dual-channel supply chain management (SCM) are introduced in this study. Moreover, this study developed a dual-channel supply chain model under customization with SSMD policy along with make-to-order, uncertain demand, controllable lead time, and distribution-free approach. All these attributes in a single model are rarely found in the existing literature.

The objective of this paper is to develop an efficient and improved customization policy in dual-channel SCM. The aim of this study is to obtain the managerial decision under demand uncertainty and price sensitivity with distributionfree approach. The competitions between online vs. retail channel, dual-channel vs. retail channel, and dual-channel vs. online channel are shown in this article to determine the best possible channel to be adopted by the company. Another vital objective of this research is to analyze the effect of migration of customers between the channels on supply chain profitability under a fixed and specified threshold value of selling price which was not yet studied by any existing literature. The effect of the variation of selling price on customer demand and supply chain profit is also an important matter of concern.

The proposed study retains some important research questions which are illustrated as follows:

(a) What is the effect of the demand uncertainty on the profit of the firm?

(b) How to determine that which channel should be adopted so that profit of the firm maximizes?

(c) How profitability of the firm is affected if selling prices exceed the fixed and specified threshold limit?

(d) How does the transfer rate of consumers from online channel to retail channel or vice versa affect optimal decision?

The entire paper is split into several sections to deal with different aspects such as description of study, literature review, and mathematical modelling. Sections 1 and 2 describe introduction and literature review, respectively. Section 3 explains the important research questions and aim of study. Section 4 depicts problem definition, assumptions, and notation to develop the mathematical modelling. Section 5 elaborates the entire mathematical model and analytical expressions of decision variables along with some propositions and corollaries. Solution technique (algorithm) of the model is also described in this section. Section 6 deals with numerical experiments and model validation. The managerial decisions are obtained by using a set of input parameters, and results are analyzed with graphical representations and sensitivity analysis. The important discussions about the outcomes are also described in this section. Lastly, in Section 7, conclusions regarding the study are depicted.

\section{Literature Review}

2.1. Dual-Channel Supply Chain. In recent years, study on dual-channel supply chain has gained reasonable attention among the researchers throughout the globe. However, most of the studies focused on pricing decisions and channel coordination. In this technologically advanced era, every player involved in the supply chain (customers, manufacturers, and retailers) expects the availability of the information of product. Consequently, Tsay and Agrawal [2], Wilder [4], and Mukhopadhyay et al. [20] stated that these expectations can be fulfilled if companies have smooth supply chain flow. Moreover, Takahashi et al. [6] expressed that through the dual-channel supply chain, customers are provided with two options, ordering of the standard product through retail channel and the customized product through online channel.

From health care providers (Medlife: India's largest e-health platform which provides medicine through online 
platform) to retailers (Wal-Mart, RT-Mart, and Metro), organizations are under great strain to meet the expectations of the customers and to stay ahead of the competition while controlling costs $[9,21]$. Moreover, online platform brings more simplicity, flexibility, and cost-effectiveness to satisfy the requirement for maximum profitability of the firm (Sana [22] and Hosseini-Motlagh et al. [23]). In addition to this, online sales provide customer feedback which is helpful to the manufacturer in revealing emerging trends, changing attributes, and opportunities to enhance customer value [14]. Furthermore, to cater wide range of consumer groups, multiple product variety needs to be provided by the industry [24]. Furthermore, industrialists are encouraged to use green technologies for sustainable development $[25,26]$.

\subsection{Centralized Dual-Channel Supply Chain with} Customization. Customization is primarily the action of modifying something (product) to suit a particular individual or task. MyVirtualModel, a Montreal-based technology provider and its roster of partners (including Adidas, Best Buy, Levi's, and Sears), enables consumers to build a vertical model of themselves, an "avatar." This means that customers can try on clothes virtually. Consumers of BMW's Mini Cooper can use an online toolkit to design the car's roof, which is then produced with an advanced digital printing system on a special foil (Salvador et al. [27]). Moreover, many companies are adopting mass customization technologies to satisfy the growing individualization of demand [28-32]. Henceforth, Figure 1 exemplifies the customization policy in the centralized dual-channel supply chain model. Customization policy could be implemented with the introduction of dual-channel strategy which further leads to the complexity in SCM as companies need to redesign the supply chain structure according to the demand of customers [6].

\subsection{Comparison between Online and Offline Channels.} According to Zhang et al. [33] in a dual-channel policy, the competition between online and retail channels and how to mitigate the effect of adopting an online channel on the retail channel are important matters to be concerned. In this stream of research, Kaya et al. [34], Yan and Pei [12], and Dan et al. [17] studied the role of the retailer and traditionalonline competition in a dual-channel supply chain. Initially, Kaya et al. [34] concluded that the optimal channel strategy is influenced by the choices of the customers between traditional channel and online channel. Later on Yan and Pei [12] observed that supply chain performance can be improved with the improvement of retail service, which was later on manifested by Dan et al. [17]. Furthermore, Hua et al. [35] scrutinized the optimal prices of a dual-channel supply chain under centralized and decentralized environment considering the delivery lead time. In addition, they also proved that the customer's acceptance of online channel greatly influences the supply chain. Moreover, Li et al. [36] demonstrated the acceptance of the customers' online channel over retail channel along with customers' sensitivity towards product differences. Customers' choices have an

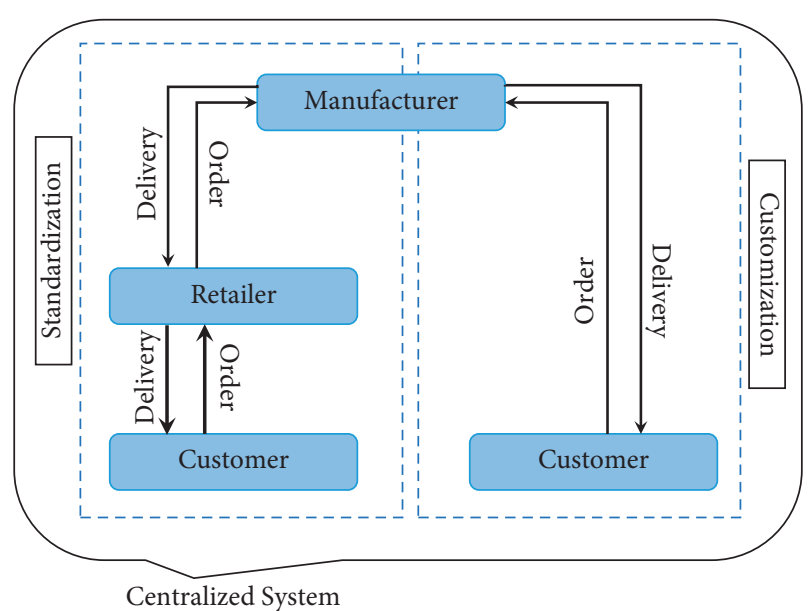

Figure 1: Dual-channel centralized system.

impactful influence on firms' decision of offering the customized products. Batarfi et al. [37] demonstrated that adding a customized product through online channel increases the profit of centralized supply chain system though it creates a conflict due to competition between the retail and online channels. Moreover, Huang et al. [15] and $\mathrm{He}$ et al. [38] examined centralized and decentralized supply chain and pricing decisions in a dual-channel supply chain model under uncertain demand.

\subsection{Dual-Channel Supply Chain under Demand Uncertainty.} In past decades, researchers have been working on stochastic demand in the dual-channel supply chain model. Chiang and Monahan [39] contemplated price independent stochastic demand in the traditional and online channel. Yao et al. [40] proved that information sharing in the dual-channel supply chain model can be beneficial for the firm which yields better profitability then noncoordinating supply chain. Furthermore, Modak and Kelle [41] adopt price and lead time-dependent random demand for the make-to-order and maketo-stock production system. Dumrongsiri et al. [42] concluded that demand variation greatly influences the equilibrium prices and the manufacturer's inspiration in adopting online channel. Moreover, He et al. [43] demonstrated how the manufacturer can inspire the retailer to expand its business by adopting the dual-channel supply chain model under stochastic demand. The article also depicted that price sharing decision of the manufacturer can actually act as a boon for the retailer. Furthermore, Roy et al. [44] developed a dual-channel supply chain model under stochastic demand to ascertain the optimal stock level, prices, and promotion effort.

2.5. The Distribution-Free Approach. Occasionally, random demand might follow a well-known distribution, but if lean information about demand fluctuation over time is available, the distribution-free approach might be a better tool for decision-making. According to Moon et al. [45], there is always inclination towards normal distribution in case of random demand disregarding other distribution with the same mean and variance. Scarf [46] solved the newsvendor 
problem with the distribution-free approach with a known mean and variance. The article considered the maximum of the lower bounds of the expected profit for all possible distribution functions.

Hua et al. [35] and Xu et al. [47] assumed deterministic demand without inventory consideration in the dual-channel supply chain model for considering decisions of delivery lead time and prices. Yang et al. [48] introduced the newsvendor model in dual-channel supply chain. In this model, they scrutinized the switching behavior of the customers depending upon availability of the product and lead time, but effects of price on demand were neglected. Table 1 enlists the research which inspires this article to consider a preassigned threshold value that is a limit beyond which if the selling price increases, the customers migrate from one traditional channel to online channel or vice versa when the demand is assumed to be variable additive stochastic demand. Moreover, this work applies distribution-free approach.

2.6. Research Gap. The dual-channel supply chain management with customization policy has been studying by many researchers and scientists. Previous studies consider that customer shifting between the channels is invariant. It is not necessary that the all customers who left a channel should mandatorily shift to the other channel. Some customers may be reluctant to purchase also. Thus, equal shifting of customers may not be practical in modern market scenario. The condition of equal customer shifting is relaxed in this article. Moreover, there is a possibility that no customers may shift to the other channel. This happens due to many reasons such as inability to purchase due to high selling price. Thus, a specified threshold limit is considered. The threshold limit is a specified positive numeric value. Customer switch only happens if the difference between the selling prices of online and offline channels is greater than the threshold limit. The concept of threshold value is incorporated as a pioneer approach. Moreover, till now either variable demand or stochastic demand was used, but pricesensitive stochastic demand is rarely assumed in literature. Therefore, this article extends the previous dual-channel models with unequal customer shipment, specific threshold limit, and price sensitive stochastic demand under distribution-free approach.

\section{Problem Definition, Assumptions, and Notation}

This section explains the problem definition, assumptions, and notation used to formulate the mathematical model of this paper.

3.1. Problem Definition. A comparison between a traditional offline and online channel on the supply chain model with a single manufacturer and single retailer is framed in this study. Most of the literature studies used either probabilistic uncertainty or demand variability, but a few articles were found which considered both of the characteristics simultaneously in a demand function. In addition to that, this paper uses max-min distribution-free approach to deal with the stochastic uncertainty along with price sensitivity. Moreover, demand data or the exact mean and standard deviation is required for estimating a probability distribution of demand which is money as well as time consuming. Therefore, to overcome all these constraints, this study considers distribution-free approach to obtain managerial decisions with the help of known mean and standard deviation.

To implement an online channel, the manufacturer and retailer should negotiate properly as a threshold value has been incorporated in this article. The threshold value signifies that if the price difference between online and offline exceeds beyond a specified limit, then customers migrate from retail channel to online channel or vice versa which should influence the profit of the channels individually along with the firm as a whole.

3.2. Assumptions. Following points enlist the various assumptions assumed for formulating the mathematical model:

(1) The company adopts the centralized dual-channel supply chain model which is assumed with customization strategy. Hence, the product is available to customers through a retailer channel and an Internet-based direct channel. Furthermore, demand is deemed to be variable as well as random [41].

(2) The manufacturer has its own manufacturing house where standardized and customized products are manufactured and does not need to invest in adopting a mass customization system [37].

(3) In case of retail channel which is selling standard product, common cycle time is considered for the manufacturer and the retailer. Moreover, in case of customization process, the manufacturer has different cycle time for production of core product used in customization.

(4) A proportion of the number of customer who refuses to purchase items through retail channel chooses to purchase customized product [41].

(5) Production rates for standard and customized products are greater than the base demand that is no shortages are allowed.

(6) Lead time is considered to be zero between the manufacturer and the retailer along with the supplier (who supplies the additional custom features) and the manufacturer [37].

(7) Single-setup multiple-delivery policy is used to deliver the product in retail channel, whereas make-toorder policy is used for online channel.

(8) When the selling price difference of the online and offline channel falls within a fixed and preassigned limit (threshold limit), no customer shifting would occur.

(9) All input parameters in this paper are positive. 
TABLE 1: Related literature.

\begin{tabular}{|c|c|c|c|c|c|c|c|c|c|c|}
\hline Author's name & DCSC & SP & $\mathrm{CP}$ & UCS & SSMD & MTO & DU & DFA & CLT & $\mathrm{MM}$ \\
\hline Chiang et al. [21] & $\sqrt{ }$ & $\sqrt{ }$ & & & & & & & & \\
\hline Tsay and Agrawal [2] & $\sqrt{ }$ & $\sqrt{ }$ & & & & & & & & \\
\hline Chiang and Monahan [39] & $\sqrt{ }$ & $\sqrt{ }$ & & & & & & & & \\
\hline Yue and Liu [49] & $\sqrt{ }$ & $\sqrt{ }$ & & & & & $\sqrt{ }$ & & & \\
\hline Kaya et al. [34] & $\sqrt{ }$ & $\sqrt{ }$ & & & & & $\sqrt{ }$ & & $\sqrt{ }$ & \\
\hline Yan and Pei [12] & $\sqrt{ }$ & $\sqrt{ }$ & & & & & & & & \\
\hline Hua et al. [35] & $\sqrt{ }$ & $\sqrt{ }$ & & & & & & & $\sqrt{ }$ & \\
\hline Takahashi et al. [6] & $\sqrt{ }$ & $\sqrt{ }$ & & & & & & & & \\
\hline Dan et al. [17] & $\sqrt{ }$ & $\sqrt{ }$ & & & & & & & & \\
\hline Jing et al. [14] & $\sqrt{ }$ & $\sqrt{ }$ & $\sqrt{ }$ & & & & & & & \\
\hline Shao $[18]$ & $\sqrt{ }$ & $\sqrt{ }$ & $\sqrt{ }$ & & & $\sqrt{ }$ & & & $\sqrt{ }$ & \\
\hline Li et al. [36] & $\sqrt{ }$ & $\sqrt{ }$ & $\sqrt{ }$ & & & $\sqrt{ }$ & & & & \\
\hline Zhang and Choi [3] & $\sqrt{ }$ & $\sqrt{ }$ & & & & & & & & \\
\hline Batarfi et al. [37] & $\sqrt{ }$ & $\sqrt{ }$ & $\sqrt{ }$ & & & $\sqrt{ }$ & & & $\sqrt{ }$ & $\sqrt{ }$ \\
\hline Moon et al. [45] & & & & & & & & $\sqrt{ }$ & & \\
\hline Yang et al. [48] & $\sqrt{ }$ & $\sqrt{ }$ & & & & & $\sqrt{ }$ & & $\sqrt{ }$ & \\
\hline Majumder et al. [50] & & & & & $\sqrt{ }$ & & & $\sqrt{ }$ & $\sqrt{ }$ & \\
\hline Modak and Kelle [41] & $\sqrt{ }$ & $\sqrt{ }$ & $\sqrt{ }$ & & & & $\sqrt{ }$ & $\sqrt{ }$ & $\sqrt{ }$ & \\
\hline Majumder et al. [51] & & & & & $\sqrt{ }$ & & & & $\sqrt{ }$ & \\
\hline Sarkar et al. [52] & & & & & $\sqrt{ }$ & & $\sqrt{ }$ & & & \\
\hline Zhou et al. [13] & $\sqrt{ }$ & $\sqrt{ }$ & $\sqrt{ }$ & & & & & & & \\
\hline This paper & $\sqrt{ }$ & $\sqrt{ }$ & $\sqrt{ }$ & $\sqrt{ }$ & $\sqrt{ }$ & $\sqrt{ }$ & $\sqrt{ }$ & $\sqrt{ }$ & $\sqrt{ }$ & $\sqrt{ }$ \\
\hline
\end{tabular}

DCSC: dual-channel supply chain; SP: standard product; CP: customized product; UCS: unequal customer shifting from online to offline and vice versa; MTO: make-to-order; DU: demand uncertainty; DFA: distribution-free approach; CLT: controllable lead time; MM: markup margin.

3.3. Notations. Tables 2 and 3 enlist the notations used in developing the mathematical model.

\section{Mathematical Model}

This section describes the demand function, profit function, distribution-free approach optimal decision of the supply chain, and solution algorithm of this paper.

4.1. Demand Function. Customers are miscellaneous in nature in their inclination towards the standard or the customized product. Many factors influence the customer's intentions such as price, variety of products, and incapability of customers to reach out to the retail stores. Succeeding Huang et al. [15], Yue and Liu [49], Zhang et al. [53], and Raju and Roy [54], linear demand functions for the standard and customized product are considered. Following demand functions for retailer and online channels are obtained by extending the work of Huang and Swaminathan [55] and Hua et al. [35].

The demand function for offline channel is given by

$$
D_{r}=a_{1}-\beta_{1} p_{r}+\delta_{1}\left(\sum_{i=1}^{N} p_{d i}-p_{r}\right) .
$$

The demand function for online channel is given by

$$
D_{d}=a_{2}-\beta_{2} \sum_{i=1}^{N} p_{d i}-\delta_{2}\left(\sum_{i=1}^{N} p_{d i}-p_{r}\right),
$$

where the following points explain the various parameters used in demand function:
Parameters $a_{1}$ and $a_{2}$ are the number of customers without having any certain and variable components.

The price sensitivity coefficients $\beta_{1}$ of the retailer's channel and $\beta_{2}$ of the manufacturer's channel represent the amount of decrease/increase in market demand when both channels increase/decrease the price by one dollar. Thus, $\beta_{1} p_{r}$ and $\beta_{2} \sum_{i=1}^{N} p_{d i}$ represent change in customers because of price sensitivity.

$\delta_{1}$ and $\delta_{2}$ represent the shifting of customers from the offline channel to the online channel or vice versa depending upon the factor that which channel's product is having less cost in comparison to others.

A house would usually generate the same return per dollar invested irrespective of the item sold; therefore, the selling price of the standard product for the retailer is given by $p_{r}=C_{p}(1+m)^{2}$ (calculation of it is shown in Appendix A) and the selling price of customized product for the manufacturer is given by $p_{d i}=C_{d i}(1+$ $m$ ) where $m$ is a markup margin. Henceforth, $\delta_{1}\left(\sum_{i=1}^{N} p_{d i}-p_{r}\right)$ and $\delta_{2}\left(\sum_{i=1}^{N} p_{d i}-p_{r}\right)$ indicate that the change is the number of customers because of $\delta_{1}$ and $\delta_{2}$.

Assuming fixed markup margin for standard as well as customized products, we get the following equations:

$$
D_{r}=a_{1}-\beta_{1} C_{p}(1+m)+\delta_{1}(1+m)\left(\sum_{i=1}^{N} C_{d i}-C_{p}\right) \text {. }
$$

The demand function for online channel is given by 
TABLe 2: Decision variables of the model.

\begin{tabular}{lc}
\hline Decision variables & Description \\
\hline$L$ & Length of the lead time for the retailer (days) \\
$n$ & Sumber of lots delivered from the manufacturer to the retailer in one production cycle, a positive integer \\
$k$ & Quantity of the standard product ordered by the retailer (units) \\
$Q_{r}$ & Quantity of the core product ordered for customization (units) \\
$Q_{d}$ & Q
\end{tabular}

TABle 3: Parameters of the model.

\begin{tabular}{|c|c|}
\hline Parameters & Description \\
\hline$C_{p}$ & Production cost for standard product (\$/unit) \\
\hline$C_{d i}^{p}$ & Production cost for customized product $(i=1,2, \ldots N)$ (\$/unit) \\
\hline$a_{1}$ & Number of customers prefer retail channel \\
\hline$a_{2}$ & Number of customers prefer online channel \\
\hline & Production rate for the core product for eventual \\
\hline$P_{d i}$ & customization $\left(P_{d i}>a_{2}\right)$ (positive number) \\
\hline$P_{r}$ & Production rate for the standard product $\left(P_{r}>a_{1}\right)$ (positive number) \\
\hline$p_{r}$ & Retailer's selling price of the standard product $\left(p_{r}>C_{p}\right)$ (\$/order) \\
\hline$p_{d i}$ & Manufacturer's selling price of the customized product $i, i=1,2, \ldots N$ (\$/order) \\
\hline$D_{r}$ & Variable demand of retail channel (units/year) \\
\hline$D_{d}$ & Variable demand of online channel (units/year) \\
\hline$\phi_{d i}$ & Percentage of the core product stock used for customized product $(i=1,2, \ldots, N)$ \\
\hline$A_{r}$ & Ordering cost of the retailer per order (\$/order) \\
\hline$S_{r}$ & Manufacturer's setup cost for standard product (\$/setup) \\
\hline$S_{d}$ & Manufacturer's setup cost for core product for customized product ( $\$ /$ setup) \\
\hline$r_{v}$ & Holding cost rate of the manufacturer (\$/unit/unit time) \\
\hline$r_{b}$ & Holding cost rate of the retailer (\$/unit/unit time) \\
\hline$C_{b}$ & Unit production cost paid by the retailer (buyer) ( $\$ /$ unit) \\
\hline$C_{v r}$ & Unit production cost paid by the manufacturer (vendor) (\$/unit) \\
\hline$\beta_{1}$ & Price sensitivity in retail channel (customer/day) \\
\hline$\beta_{2}$ & Price sensitivity in online channel (customer/day) \\
\hline$\delta_{1}$ & Number of customers switching from retail channel to online channel \\
\hline$\delta_{2}$ & Number of customers switching from online channel to retail channel \\
\hline$h_{1}$ & Manufacturer's holding cost which includes financial cost and storage cost (\$/unit) \\
\hline$\pi$ & Unit backlogging cost for the retailer (\$/unit) \\
\hline$\sigma$ & Standard deviation of demand per unit time \\
\hline$m$ & Markup margin (percentage) \\
\hline$R$ & Reorder point of the retailer (units) \\
\hline$s$ & Safety factor of the retailer (units) \\
\hline M & Random lead time demand which has a cumulative distribution function (c.d.f) $F$ with mean DL and standard deviation $\sigma \sqrt{L}$ \\
\hline$E(\cdot)$ & Mathematical expectation \\
\hline
\end{tabular}

$$
D_{d}=a_{2}-\beta_{2}(1+m)\left(\sum_{i=1}^{N} C_{d i}\right)-\delta_{2}(1+m)\left(\sum_{i=1}^{N} C_{d i}-C_{p}\right) .
$$

4.2. Profit Functions. This section includes profit equations of the manufacturer and retailer for standard and customized products.

4.2.1. Manufacturer's Profit for Standard Product. The profit of the manufacturer per unit of time from selling the standard product through the retail channel is given by

$$
\begin{aligned}
\nabla_{1}= & \text { Revenue }- \text { Setup cost }- \text { Holding cost } \\
& - \text { Manufacturer's production cost, } \\
\nabla_{1}= & C_{p}(1+m) D_{r} \\
& -\left[\frac{S_{r} D_{r}}{n Q_{r}}+\frac{r_{v} C_{p} Q_{r}}{2}\left[n\left(1-\frac{D_{r}}{P_{r}}\right)-1+\frac{2 D_{r}}{P_{r}}\right]\right]-C_{v r} D_{r},
\end{aligned}
$$

where the following points explain the various cost components used in equation (5): 
$C_{p}(1+m) D_{r}$ is revenue and $C_{p}(1+m)$ is the selling price of the manufacturer for standard product.

$\left(S_{r} D_{r} / n Q_{r}\right)$ is setup cost for the retail channel, and the manufacturer produces integer multiple of the retailer's order quantity. Figure 2 displays that as $Q_{r}$ is the total order quantity of all retailers, the manufacturer produces $n Q_{r}$ quantity where $n$ is a positive integer. The expected cycle length of the manufacturer thus becomes $\left(D_{r} / n Q_{r}\right)$, and the setup cost of the manufacturer becomes $\left(S_{r} D_{r} / n Q_{r}\right)$.

The average inventory of the manufacturer can be calculated as

$$
\begin{aligned}
& \frac{D_{r}\left(n Q_{r}\left(\left(Q_{r} / P_{r}\right)+\left((n-1) Q_{r} / D_{r}\right)\right)-\left(n^{2} Q_{r}^{2} / 2 P_{r}\right)-\left(\left(Q_{r}^{2} / D_{r}\right)(1+2+\cdots+(n-1))\right)\right)}{n Q_{r}} \\
& =\frac{Q_{r}}{2}\left(n\left(1-\frac{D_{r}}{P_{r}}\right)-1+\frac{2 D_{r}}{P_{r}}\right) .
\end{aligned}
$$

The holding cost of the manufacturer is $\left(r_{v} C_{p} Q_{r} / 2\right)\left(n\left(1-\left(D_{r} / P_{r}\right)\right)-1+\left(2 D_{r} / P_{r}\right)\right)$. Thus, the expected holding cost per unit time per unit item is

$$
\frac{r_{v} C_{p} Q_{r}}{2}\left(n\left(1-\frac{D_{r}}{P_{r}}\right)-1+\frac{2 D_{r}}{P_{r}}\right) \text {. }
$$

$C_{v r} D_{r}$ represents the manufacturer's production cost for standard product.

4.2.2. Manufacturer's Profit for Customized Product. Figure 3 exhibits the online channel inventory of the manufacturer, whereas the profit of the manufacturer per unit of time from selling the customized product through the online channel is given by

$$
\begin{aligned}
\nabla_{2}= & \text { Revenue }- \text { Setup cost }- \text { Holding cost } \\
& - \text { Manufacturing cost } \\
\nabla_{2}= & \sum_{i=1}^{N} C_{d i}(1+m) \phi_{d i} D_{d} \\
& -\left[\frac{S_{d} D_{d}}{Q_{d}}+\left(\frac{h_{1} Q_{d}}{2}\right)\left(1-\frac{D_{d}}{P_{d}}\right)+\sum_{i=1}^{N} C_{d i} \phi_{d i} D_{d}\right],
\end{aligned}
$$

where the following points explain the various cost components used in equation (5):

$\sum_{i=1}^{N} C_{d i}(1+m) \phi_{d i} D_{d} \quad$ is revenue, and $\sum_{i=1}^{N} C_{d i}$ $(1+m) \phi_{d i}$ is the selling price of the manufacturer for customized product.
$\left(S_{d} D_{d} / Q_{d}\right)$ is setup cost as the manufacturer follows make-to-order policy where he manufactures the product on demand by the customer. $Q_{d}$ is the total order quantity of all customers. The expected cycle length of the manufacturer thus becomes $\left(D_{d} / Q_{d}\right)$, and the setup cost of the manufacturer becomes $\left(S_{d} D_{d} / Q_{d}\right)$. The average inventory of the manufacturer can be calculated as

$$
\text { average inventory }=\frac{Q_{d}}{2}\left(1-\frac{D_{d}}{P_{d}}\right) .
$$

The holding cost of the manufacturer is $\left(h_{1} Q_{d} / 2\right)\left(1-\left(D_{d} / P_{d}\right)\right)$.

Thus, the expected holding cost per unit time is

$$
\frac{h_{1} Q_{d}}{2}\left(1-\frac{D_{d}}{P_{d}}\right) \text {. }
$$

Each customization is composed of a production cost $\sum_{i=1}^{N} C_{d i}$, and total production cost of the vendor will be $\sum_{i=1}^{N} C_{d i} \phi_{d i} D_{d}$.

4.2.3. Retailer's Profit. Figure 4 manifests the inventory pattern between the manufacturer and retailer, whereas the profit of the retailer per unit time from selling the standard product is given by

$$
\begin{aligned}
& \nabla_{3}=\text { Revenue }- \text { Ordering cost }- \text { Holding cost }- \text { shortage cost }- \text { Lead time crashing cost }, \\
& \nabla_{3}=C_{p}(1+m)^{2} D_{r}-\left[\frac{A_{r} D_{r}}{Q_{r}}+r_{b} c_{b}\left(\frac{Q_{r}}{2}+R-D_{r} L\right)+\frac{\pi D_{r}}{Q_{r}} E(M-R)^{+}+\frac{D_{r} C L}{Q_{r}}\right],
\end{aligned}
$$




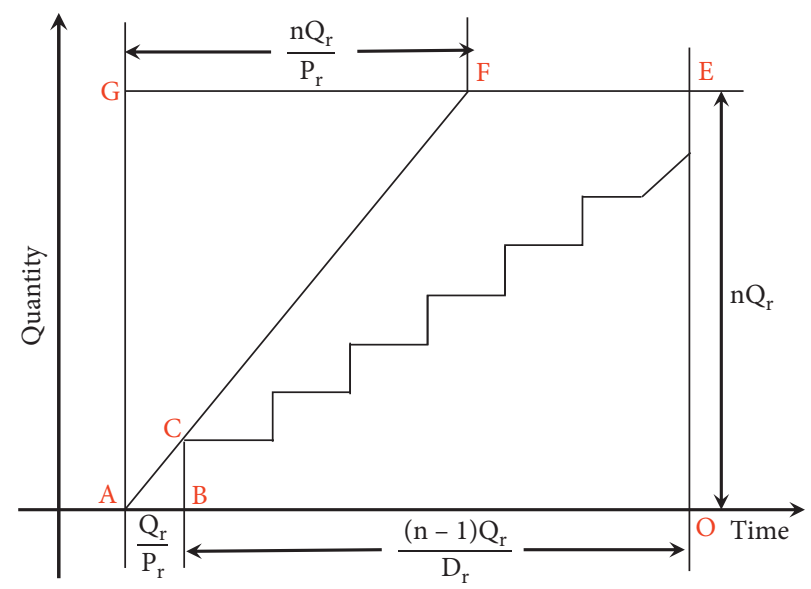

FIGURE 2: Manufacture's inventory position.

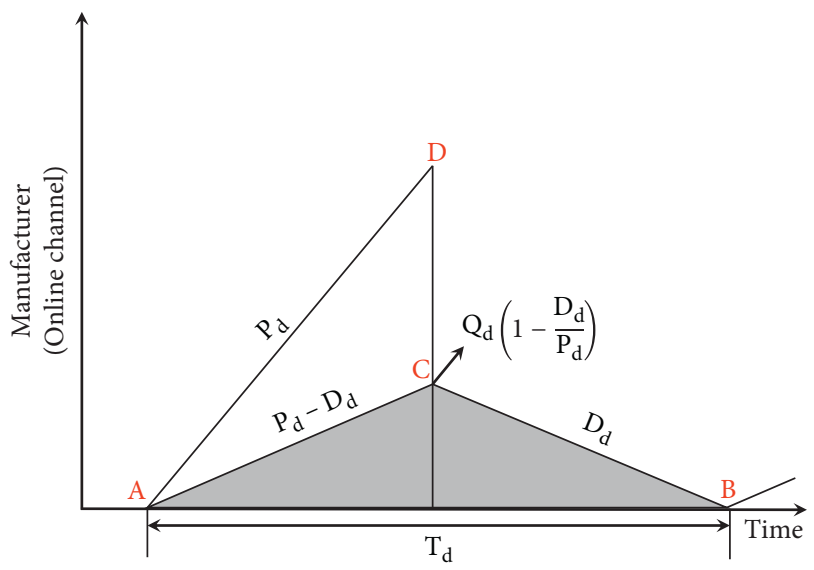

FIgURE 3: Manufacture's online channel inventory under the EPQ model.

where the following points explain the various cost components used in equation (11):

$C_{p}(1+m)^{2} D_{r}$ represents revenue of the retailer. $C_{p}(1+m)^{2}$ is the selling price for the retailer for standard product.
The ordering cost per unit time for the retailer is $\left(A_{r} D_{r} / Q_{r}\right)$.

When the level of inventory reaches the reorder point $R$, quantity $Q$ is ordered by the retailer. $R-D_{r} L$ represents the expected level of inventory before the order is received by the retailer, whereas $Q+R-D_{r} L$ represents expected inventory level immediately after the delivery of quantity $Q$. Consequently, $(Q / 2)+R-D_{r} L$ is the average inventory over a cycle. Henceforth, the retailer's expected holding cost per unit time is $r_{b} c_{b}\left(\left(Q_{r} / 2\right)+R-D_{r} L\right)$.

$\mathrm{M}$ is the stochastic lead time demand, and $R$ is the reorder point for the retailer; then, the expected shortage at the end of the cycle is expressed as $E(M-R)^{+}$for the retailer resulting into $\left(\pi D_{r} / Q_{r}\right) E(M-R)^{+}$as shortage cost.

The lead time crashing cost per unit time is $\left(D_{r} C L / Q_{r}\right)$.

Total profit of the single-channel supply chain $\nabla_{S}$ is given by adding $\nabla_{1}, \nabla_{3}$. We get

$$
\begin{aligned}
\nabla_{S}= & \nabla_{1}+\nabla_{3} \\
\nabla_{S}= & C_{p}(1+m) D_{r}-\left[\frac{S_{r} D_{r}}{n Q_{r}}+\frac{r_{v} C_{p} Q_{r}}{2}\left[n\left(1-\frac{D_{r}}{P_{r}}\right)-1+\frac{2 D_{r}}{P_{r}}\right]\right]-C_{v r} D_{r} \\
& +C_{p}(1+m)^{2} D_{r}-\left[\frac{A_{r} D_{r}}{Q_{r}}+r_{b} c_{b}\left(\frac{Q_{r}}{2}+R-D_{r} L\right)+\frac{\pi D_{r}}{Q_{r}} E(M-R)^{+}+\frac{D_{r} C L}{Q_{r}}\right] .
\end{aligned}
$$

4.3. Distribution-Free Approach. We elaborate the distribution-free approach by using the following points:

Any specific probability distribution should not be considered for any random variable in this approach. A class of cumulative distribution function (c.d.f) having mean $D_{r} L$ and standard deviation $\sigma \sqrt{L}$ is considered.

The max-min distribution-free approach is applied to obtain the values of the decision variables, in this approach, initially the worst possible case (i.e., the 


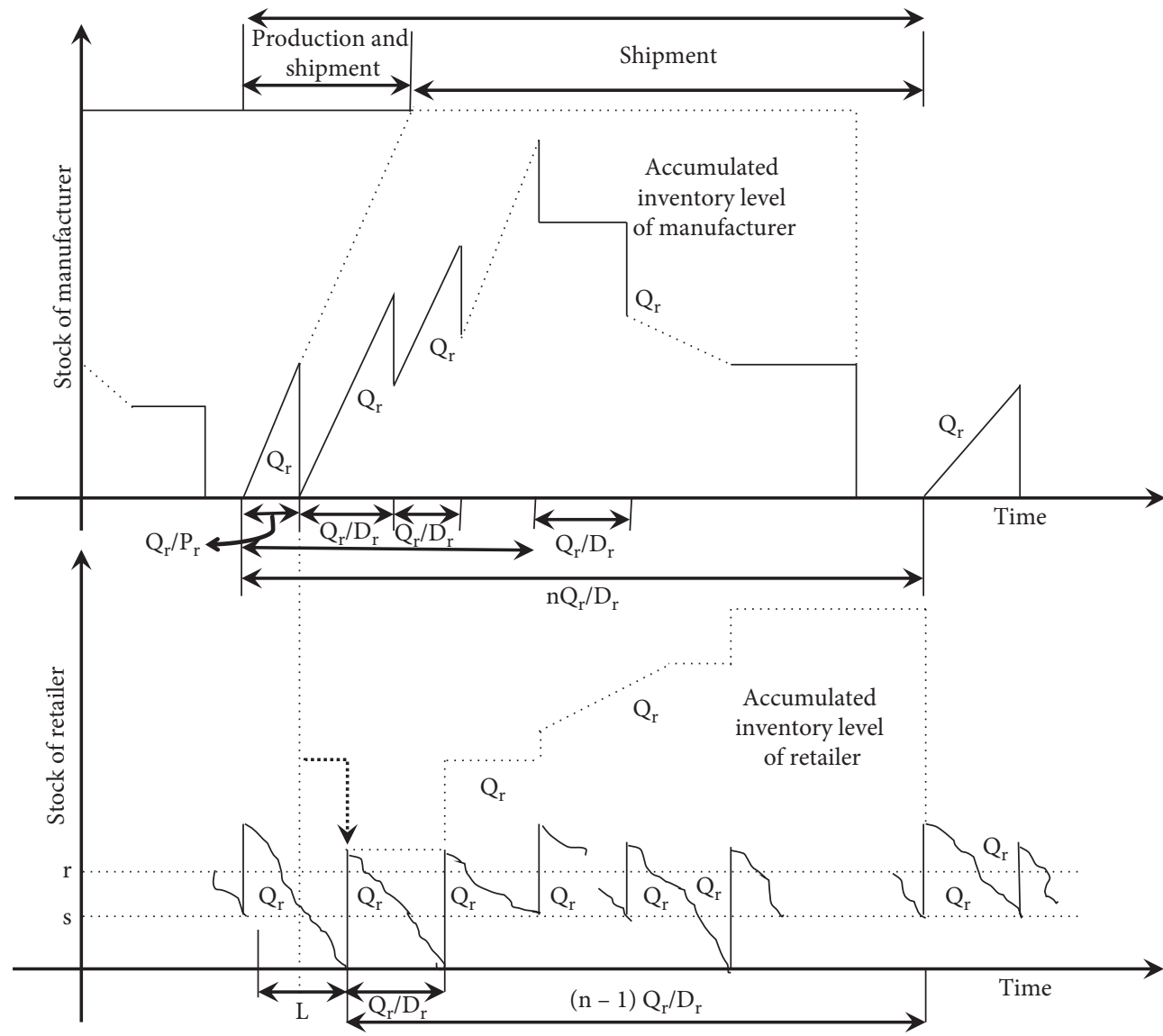

FIgURE 4: Manufacture's and retailer's inventory pattern.

expression for minimum profit is obtained which is then maximized for the best profitability).

The method was first used by Gallego and Moon [56] as a mini-max approach to obtain the minimum value of cost function. This approach was utilized to deal with the uncertain demand only.

In this article, we use a max-min method for profit maximization which is the opposite of Gallego and Moon's [56] min-max distribution-free approach. Moreover, instead of assuming only uncertainty, this article provides demand variability also. Therefore, a modification is added in the inequality used by Moon and Gallego [56] with a max-min approach and incorporation of variability in demand function.

The lead time demand $M$ is depending on $D_{r}$ which further depends on the selling price of the retailer $C_{p}(1+m)^{2}$ which leads to variability in the demand. Moreover, randomness in demand is accomplished in additive form (Petruzzi and Dada [57], Sarkar et al. [58], and Modak and Kelle [41]).

The inequality stated by Proposition 1 is applied to solve the model.

\section{Proposition 1}

$$
\begin{aligned}
E(M-R)^{+} & =E\left(\left(D_{r} L+X\right)-R\right)^{+} \\
& \leq\left[\frac{\sqrt{\sigma^{2} L+\left(D_{r} L\right)^{2}+k^{2} \sigma^{2} L-2 D_{r} L k \sigma \sqrt{L}}+\left(D_{r} L-k \sigma \sqrt{L}\right)}{2}\right] .
\end{aligned}
$$

Moreover, the upper bound of the above inequality is tight. In the equation, $R=D_{r} L+k \sigma \sqrt{L}$ is reorder point, $D_{r} L$ is the lead time demand, $k \sigma \sqrt{L}$ is safety stock, and $k$ is a safety factor.
Proof. See Appendix B.

Thus, using inequality (10), the expected total profit of the centralized single-channel supply chain $\nabla_{S}$ is given by adding $\nabla_{1}$ and $\nabla_{3}$. We get 


$$
\begin{aligned}
\nabla_{S}= & C_{p}(1+m) D_{r}-\frac{A_{r} D_{r}}{Q_{r}}-r_{b} c_{b}\left(\frac{Q_{r}}{2}+k \sigma \sqrt{L}\right)-\frac{D_{r} C L}{Q_{r}} \\
& -\frac{\pi D_{r}}{Q_{r} 2}\left[\sqrt{\sigma^{2} L+\left(D_{r} L\right)^{2}+k^{2} \sigma^{2} L-2 D_{r} L k \sigma \sqrt{L}}+\left(D_{r} L-k \sigma \sqrt{L}\right)\right] \\
& +C_{p}(1+m)^{2} D_{r}-\left[\frac{S_{r} D_{r}}{Q_{r} n}+\frac{r_{v} Q_{r}}{2}\left[n\left(1-\frac{D_{r}}{P_{r}}\right)-1+\frac{2 D_{r}}{P_{r}}\right]\right]-C_{v r} D_{r} .
\end{aligned}
$$

And expected total profit of the centralized dual-channel supply chain $\nabla_{D}$ is given by adding $\nabla_{1}, \nabla_{2}$, and $\nabla_{3}$. We get

$$
\begin{aligned}
\nabla_{D}= & C_{p}(1+m) D_{r}-\left[\frac{S_{r} D_{r}}{n Q_{r}}+\frac{r_{v} C_{p} Q_{r}}{2}\left[n\left(1-\frac{D_{r}}{P_{r}}\right)-1+\frac{2 D_{r}}{P_{r}}\right]\right]-C_{v r} D_{r} \\
& +\sum_{i=1}^{N} C_{d i}(1+m) \phi_{d i} D_{d}-\left[\frac{S_{d} D_{d}}{Q_{d}}+\left(\frac{h_{1} Q_{d}}{2}\right)\left(1-\frac{D_{d}}{P_{d}}\right)+\sum_{i=1}^{N} C_{d i} \phi_{d i} D_{d}\right] \\
& +C_{p}(1+m)^{2} D_{r}-\left[\frac{A_{r} D_{r}}{Q_{r}}+r_{b} c_{b}\left(\frac{Q_{r}}{2}+k \sigma \sqrt{L}\right)+\frac{D_{r} C L}{Q_{r}}\right] \\
& -\frac{\pi D_{r}}{Q_{r} 2}\left[\sqrt{\sigma^{2} L+\left(D_{r} L\right)^{2}+k^{2} \sigma^{2} L-2 D_{r} L k \sigma \sqrt{L}}+\left(D_{r} L-k \sigma \sqrt{L}\right)\right]
\end{aligned}
$$

4.4. Optimal Decision of the Supply Chain. Since, equations (17) are nonlinear in nature so for a fixed positive integer $m$, we take partial derivative of the profit with respect to $Q_{d}, Q_{r}$, and $k$ to obtain the optimal solution:

$$
\begin{aligned}
\frac{\partial \nabla_{D}}{\partial k}= & \left(-r_{b} C_{b} \sigma \sqrt{L}-\frac{\pi D_{r}}{2 Q_{r}}\left[\frac{k \sigma^{2} L-D_{r} L \sigma \sqrt{L}}{\sqrt{\sigma^{2} L+\left(D_{r} L\right)^{2}+k^{2} \sigma^{2} L-2 D_{r} L k \sigma \sqrt{L}}}-\sigma \sqrt{L}\right]\right) \\
\frac{\partial \nabla_{D}}{\partial Q_{r}}= & \frac{A_{r} D_{r}}{Q_{r}^{2}}-\frac{r_{b} c_{b}}{2}+\frac{S_{r} D_{r}}{n Q_{r}^{2}}+\frac{D_{r} C L}{Q_{r}^{2}}-\frac{r_{v} C_{p}}{2}\left[n\left(1-\frac{D_{r}}{P_{r}}\right)-1+\frac{2 D_{r}}{P_{r}}\right] \\
& +\frac{\pi D_{r}}{2 Q_{r}^{2}}\left[\sqrt{\sigma^{2} L+\left(D_{r} L\right)^{2}+k^{2} \sigma^{2} L-2 D_{r} L k \sigma \sqrt{L}}+\left(D_{r} L-k \sigma \sqrt{L}\right)\right] \\
\frac{\partial \nabla_{D}}{\partial Q_{d}}= & \frac{S_{d} D_{d}}{Q_{d}^{2}}-\frac{h_{1}}{2}\left(1-\frac{D_{d}}{P_{d}}\right) .
\end{aligned}
$$

Now, for fixed value of integer $m$, the value of $Q_{d}, Q_{r}$, and $k$ is obtained by equating equations (18)-(20) to zero that is 


$$
\begin{gathered}
\frac{\partial \nabla_{D}}{\partial k}=0, \\
\frac{\partial \nabla_{D}}{\partial Q_{r}}=0,
\end{gathered}
$$

$$
\frac{\partial \nabla_{D}}{\partial Q_{d}}=0
$$

and we get

$$
\begin{aligned}
Q_{d}^{*} & =\sqrt{\frac{S_{d} D_{d}}{\left(h_{1} / 2\right)\left(1-\left(D_{d} / P_{d}\right)\right)}}, \\
Q_{r}^{*} & =\sqrt{\frac{-D_{r} C L+S_{r} D_{r}+A_{r} D_{r}+\left(\pi D_{r} / 2\right) \sqrt{\sigma^{2} L+\left(D_{r} L\right)^{2}+k^{2} \sigma^{2} L-2 D_{r} L k \sigma \sqrt{L}}+D_{r} L-k \sigma \sqrt{L}}{\left(r_{b} C_{b} / 2\right)+\left(r_{v} / 2\right)\left(n\left(1-\left(D_{r} / P_{r}\right)\right)-1+2\left(D_{r} / P_{r}\right)\right)}}, \\
k^{*} & =\frac{\left(\left(-\sigma \sqrt{Q_{r} C_{b} r_{b}\left(-Q_{r} C_{b} r_{b}+\pi D_{r}\right)}\right) /\left(-Q_{r} C_{b} r_{b}+\pi D_{r}\right)\right)+\left(\left(D_{r} \pi \sigma \sqrt{Q_{r} C_{b} r_{b}\left(-Q_{r} C_{b} r_{b}+\pi D_{r}\right) L}\right) /\left(2 Q_{r} C_{b} r_{b}\left(\pi D_{r}-Q_{r} C_{b} r_{b}\right)\right)\right)+L D_{r}}{\sqrt{L} \sigma} .
\end{aligned}
$$

It can be clearly seen that the optimal solution for $Q_{r}^{*}$, $Q_{d}^{*}$, and $k^{*}$ is dependent on one another. Furthermore, a closed form expression for centralized profit function is hard to find. Therefore, finding these optimal values requires the use of a numerical procedure. An iteration method is used with the following algorithm to find the managerial decisions.

\subsection{Solution Algorithm}

Step 1: assign the values of all parameters as specified in Table 4.

Step 2: set $n=1$.

Step 3: for each value of $L_{i} ; i=1,2, \ldots$ perform the following steps.

Step 3(a): obtain the value of $Q_{d}$ from (22). Step 3(b): obtain the value of $Q_{r}$ from (25).
Step 3(c): obtain the value of $k$ from (26). Step 3(d): repeat Steps 3(a) to 3(c) until there are no changes in the values of $Q_{d}, Q_{r}$, and $k$ up to a specified accuracy level.

Step 4: use the values of $Q_{d}, Q_{r}$, and $k$ to obtain $\nabla_{S}$ from equation (14).

Step 5: use the value of $\nabla_{S}$ to obtain $\nabla_{D}$.

Step 6: set $n=n+1$ and repeat Step 3 to 5 .

Step 7: if $\nabla_{D}(n)>\nabla_{D}(n+1)$, then repeat Step 2 to Step 6 , else stop.

Proposition 2. If we represent $Q_{r}^{*}, Q_{d}^{*}$, and $k^{*}$ as the optimal values of $Q_{r}, Q_{d}$, and $k$, then for fixed values of $n$ and $L \in\left[L_{i}, L_{i-1}\right]$, the dual-channel profit function $\nabla_{D}$ attains its global maximum at $Q_{r}^{*}, Q_{d}^{*}$, and $k^{*}$ under the condition

$$
\begin{aligned}
& \left(A_{r}+\frac{S_{r}}{n}+C L\right) \frac{\sigma^{4} L^{2}}{\sqrt{\sigma^{2} L+\left(D_{r} L\right)^{2}+k^{2} \sigma^{2} L-2 D_{r} L \sigma \sqrt{L}}}+\pi \sigma^{4} L^{2} \\
& +\frac{\pi k \sigma^{3} L \sqrt{L}}{2 \sqrt{\sigma^{2} L+\left(D_{r} L\right)^{2}+k^{2} \sigma^{2} L-2 D_{r} L \sigma \sqrt{L}}}+\frac{D_{r} \sigma^{3} L^{2} \sqrt{L}}{\sigma^{2} L+\left(D_{r} L\right)^{2}+k^{2} \sigma^{2} L-2 D_{r} L \sigma \sqrt{L}} \\
& >\frac{D_{r} L^{2} \sigma^{2}}{2 \sqrt{\sigma^{2} L+\left(D_{r} L\right)^{2}+k^{2} \sigma^{2} L-2 D_{r} L \sigma \sqrt{L}}}+\frac{\pi\left(2 k^{2} \sigma^{4} L^{2}+\sigma^{4} L^{2}+2 D_{r}^{2} L^{3} \sigma^{2}\right)}{4\left(\sigma^{2} L+\left(D_{r} L\right)^{2}+k^{2} \sigma^{2} L-2 D_{r} L \sigma \sqrt{L}\right)}
\end{aligned}
$$


TABLE 4: Input parameters.

\begin{tabular}{|c|c|c|}
\hline Input parameter & Value & Unit \\
\hline$C_{p}$ & 100 & \$/unit \\
\hline$C_{d 1}^{P}$ & 80 & \$/unit \\
\hline$C_{d 2}$ & 100 & $\$$ /unit \\
\hline$C_{d 3}$ & 120 & \$/unit \\
\hline$S_{r}$ & 800 & $\$ /$ setup \\
\hline$S_{d}$ & 1000 & $\$ /$ setup \\
\hline$C_{v r}$ & 100 & $\$ /$ unit \\
\hline$C_{b}$ & 120 & \$/unit \\
\hline$r_{v}$ & 0.2 & (\$/unit)/unittime \\
\hline$r_{b}$ & 0.2 & (\$/unit)/unittime \\
\hline$A_{r}$ & 200 & $\$$ /order \\
\hline$P_{r}$ & 5000 & Units/year \\
\hline$P_{d}$ & 5000 & Units/year \\
\hline$\pi$ & 150 & \$/unit \\
\hline$a_{1}$ & 1000 & $(-)$ \\
\hline$a_{2}$ & 1000 & $(-)$ \\
\hline$\beta_{1}$ & 0.75 & $\$$ /unit \\
\hline$\beta_{2}$ & 0.80 & \$/unit \\
\hline$\delta_{1}$ & 0.2 & $(-)$ \\
\hline$\delta_{2}$ & 0.3 & $(-)$ \\
\hline$\phi_{d 1}$ & 0.25 & $\%$ \\
\hline$\phi_{d 2}$ & 0.3 & $\%$ \\
\hline$\phi_{d 3}$ & 0.45 & $\%$ \\
\hline$h_{1}$ & 30 & (\$/unit)/year \\
\hline$L$ & 4 & Weeks \\
\hline$\sigma$ & 200 & $(-)$ \\
\hline$m$ & 0.7 & $(-)$ \\
\hline
\end{tabular}

Proof. See Appendix C

Proposition 3. If we represent $Q_{r}^{*}, k^{*}$ as the optimal values of $Q_{r}, k$, then for fixed values of $n$ and $L \in\left[L_{i}, L_{i-1}\right]$, the single- channel profit function $\nabla_{S}$ attains its global maximum at $Q_{r}^{*}$, $k^{*}$ under the condition

$$
\begin{aligned}
& \left(A_{r}+\frac{S_{r}}{n}+C L\right) \frac{\sigma^{4} L^{2}}{\sqrt{\sigma^{2} L+\left(D_{r} L\right)^{2}+k^{2} \sigma^{2} L-2 D_{r} L \sigma \sqrt{L}}} \\
& +\pi \sigma^{4} L^{2}+\frac{\pi k \sigma^{3} L \sqrt{L}}{2 \sqrt{\sigma^{2} L+\left(D_{r} L\right)^{2}+k^{2} \sigma^{2} L-2 D_{r} L \sigma \sqrt{L}}}+\frac{D_{r} \sigma^{3} L^{2} \sqrt{L}}{\sigma^{2} L+\left(D_{r} L\right)^{2}+k^{2} \sigma^{2} L-2 D_{r} L \sigma \sqrt{L}} \\
& >\frac{D_{r} L^{2} \sigma^{2}}{2 \sqrt{\sigma^{2} L+\left(D_{r} L\right)^{2}+k^{2} \sigma^{2} L-2 D_{r} L \sigma \sqrt{L}}}+\frac{\pi\left(2 k^{2} \sigma^{4} L^{2}+\sigma^{4} L^{2}+2 D_{r}^{2} L^{3} \sigma^{2}\right)}{4\left(\sigma^{2} L+\left(D_{r} L\right)^{2}+k^{2} \sigma^{2} L-2 D_{r} L \sigma \sqrt{L}\right)} .
\end{aligned}
$$

Proof. See Appendix D

Corollary 1. From equation (3), it is observed that the terms associated with $C_{p}$ are negative in $D_{r}$ equation which clearly shows that as $C_{p}$ increases $D_{r}$ decreases, i.e.,

$$
D_{r} \propto \frac{1}{C_{p}}
$$

$$
\Longrightarrow C_{p} \propto \frac{1}{D_{r}} \text {. }
$$


Furthermore, from equations (14) and (15), we get

$$
\begin{aligned}
& \nabla_{D} \propto D_{r}, \\
& \nabla_{S} \propto D_{r}
\end{aligned}
$$

which implies that as $D_{r}$ decreases because of increase $C_{p}, \nabla_{D}$ and $\nabla_{S}$ decrease as fast rate which we can observe from Table 5 .

Corollary 2. From equation (4) it is observed that the terms associated with $\sum_{i=1}^{N} C_{d i}$ are negative $D_{d}$ equation which clearly shows that as $\sum_{i=1}^{N} C_{d i}$ increases, $D_{d}$ decreases, i.e.,

$$
\begin{gathered}
\text { i.e., } D_{d} \propto \frac{1}{\sum_{i=1}^{N} C_{d i}}, \\
\Longrightarrow \sum_{i=1}^{N} C_{d i} \propto \frac{1}{D_{d}},
\end{gathered}
$$

which implies that as $\sum_{i=1}^{N} C_{d i}$ increases, $D_{d}$ decreases.

Furthermore, from equations (15), we get

$$
\nabla_{D} \propto D_{d}
$$

which implies that as $D_{d}$ decreases because of increase $C_{d}$, $\nabla_{D}$ increases at slow rate in comparison to otherwise which we can observe from Table 6.

\section{Numerical Experimentation and Discussion}

In Table 4, we have enlisted the input parameters used for numerical experiments.

5.1. Profit Analysis. We consider an example to compare the profit of the dual-channel and single-channel supply chain management. In case of the dual-channel supply chain model, the manufacturer provides the standard product to the customer through offline channel and customized product through online channel, whereas in case of the single-channel supply chain model, the manufacturer provides only standard product to the customer through offline channel. The purpose of this section is to examine and analyze the managerial decisions under various circumstances. We assume that three types of customizations are offered on standard product in case of the dual-channel supply chain model to the customers.

The values of parameters to obtain the numerical results are enlisted in Table 4 . The threshold value is preassigned with the value $\$ 20$ for all cases throughout the paper.

Using the values of parameters, we obtain the optimal values of the decision variables, illustrated by Table 7 . It is observed from Table 7 that maximum profits for both singleand dual-channel supply chain are obtained as 782670.28 and 822508.59 , respectively. The maximum profits are observed at $n=2$, and the corresponding values of $k, L, Q_{r}, Q_{d}, D_{r}$, and $D_{d}$ are 5.58, 4, 1058.21, 166.22, 490, and 456 , respectively.

Moreover, Table 8 shows that if the selling price of the standard product is more than that of customized product, then shifting of customers from the retailer shop to online platform is more, i.e., $\delta_{1}>\delta_{2}$. Furthermore, if the selling price of the standard product is less than that of customized product, then shifting of customers from the retailer shop to online platform is less, i.e., $\delta_{1}<\delta_{2}$. Moreover, it also depicts that in either of case profit of dual-channel is more in comparison to single channel.

\subsection{Price Sensitivity in Demand When Selling Price Difference} between Online and Offline Mode Is Greater Than the Preassigned Threshold Limit. To analyze the effect of changing selling price of standard and customized product on the demand as well as profit for both dual- and single-channel supply chain, two cases are considered for price sensitivity analysis. Case 1 represents the effect of changing the selling price of standard product on demand and profit (Table 7), whereas Case 2 shows the same for varying selling price of customized product (Table 8).

Both cases are analyzed when the selling price difference of retail and online channel is more than the preassigned threshold limit, i.e., $\left|\sum_{i=1}^{3} C_{d i}-C_{p}\right|>20$.

5.2.1. Case 1. In this case, the selling prices of customized products are kept as constant and the selling price of standard product is varying. The results are shown in Table 5 as well as in Figure 5.

5.2.2. Case 2. The selling price of standard product is kept as constant, and the selling price of customized products is varying in this case. We consider the variation of the sum of selling prices of all customizations, i.e., $\sum_{i=1}^{3} C_{d i}$. The results are shown in Table 6 as well as in Figure 6.

5.3. Price Sensitivity in Demand When Selling Price Difference between Online and Offline Mode Is Less Than the Preassigned Threshold Limit. Similar analysis is performed by considering two different cases as described in Section 6.3. However, the price difference between online and offline mode is less than the fixed and specified threshold limit, i.e., $\left|\sum_{i=1}^{3} C_{d i}-C_{p}\right|<20$.

Two cases are set out as follows.

5.3.1. Case 1. The selling prices of customized products are set as constant, and the selling price of standard product is changing. The results are shown in Table 9 and in Figure 7.

5.3.2. Case 2. The selling price of standard product is kept as constant, and the selling price of customized products is varying in this case (as considered in Case 2 of Section 6.3). The results are shown in Table 10 as well as in Figure 8.

5.4. Important Discussion and Significance of Results. Table 5 and Figure 5 illustrate that if the selling price of the customized product increases, it results in increasing difference between the selling prices of the standard and customized product. Henceforth, more number of customers shifts from customized product to standard product 
TABLe 5: Managerial decisions for $\left|\sum_{i=1}^{N} C_{d i}-C_{p}\right|>20$ (Case 1).

\begin{tabular}{lcccccccc}
\hline Sr. no. & $C_{d}=\sum_{i=1}^{3} C_{d i}$ & $C_{p}$ & $D_{r}$ & $D_{d}$ & $Q_{r}$ & $Q_{d}$ & $\nabla_{D}$ \\
\hline 1 & 400 & 300 & 439.0 & 626 & 1012.0 & 191.10 & 739598.1 & 699808.8 \\
2 & 400 & 360 & 469.6 & 524 & 1041.6 & 176.80 & 789601.1 & 749455.6 \\
3 & 400 & 420 & 500.2 & 422 & 1070.2 & 160.50 & 836828.1 & 799124.1 \\
4 & 400 & 480 & 530.8 & 320 & 1097.8 & 141.30 & 881299.4 & 848811.9 \\
5 & 400 & 540 & 561.4 & 218 & 1124.6 & 117.90 & 923055.3 & 898517.4 \\
6 & 400 & 600 & 592.0 & 116 & 1150.6 & 86.90 & 962195.4 \\
7 & 400 & 660 & 622.6 & 14 & 1175.9 & 30.51 & 999254.5 & 9978238.7 \\
8 & 400 & 665 & 625.2 & 5.5 & 1177.9 & 19.14 & 1002417 \\
9 & 400 & 667 & 626.2 & 2.1 & 1178.8 & 11.83 & 1003757 \\
10 & 400 & 668 & 626.7 & 0.4 & 1179.2 & 5.20 & 1002120 \\
\hline
\end{tabular}

TABLE 6: Managerial decisions for $\left|\sum_{i=1}^{N} C_{d i}-C_{p}\right|>20$ (Case 2).

\begin{tabular}{lcccccccc}
\hline Sr. no. & $C_{d}=\sum_{i=1}^{3} C_{d i}$ & $C_{p}$ & $D_{r}$ & $D_{d}$ & $Q_{r}$ & $Q_{d}$ & $\nabla_{D}$ \\
\hline 1 & 300 & 400 & 456.0 & 643 & 1028.59 & 193.3 & 768344.7 & 727387.5 \\
2 & 360 & 400 & 476.4 & 530.8 & 1048.10 & 177.8 & 801195.6 & 760491.2 \\
3 & 420 & 400 & 496.8 & 418.6 & 1067.10 & 160.0 & 830983.7 & 793604.4 \\
4 & 480 & 400 & 517.2 & 306.4 & 1085.70 & 138.5 & 857738.4 & 826726.2 \\
5 & 540 & 400 & 537.6 & 194.2 & 1103.90 & 111.6 & 881519.9 & 859856.1 \\
6 & 600 & 400 & 558 & 82.0 & 1121.70 & 73.3 & 902503.2 \\
7 & 610 & 400 & 561.4 & 63.3 & 1124.63 & 64.5 & 905819.4 & 89298517.4 \\
8 & 620 & 400 & 564.8 & 44.6 & 1127.56 & 54.3 & 909015.6 & 904041.2 \\
9 & 630 & 400 & 568.2 & 25.9 & 1130.47 & 41.4 & 912201.7 & 909565.2 \\
10 & 640 & 400 & 571.6 & 7.2 & 1133.38 & 21.9 & 915533.9 & 915089.4 \\
\hline
\end{tabular}

TABLE 7: Optimum values of decision variables.

\begin{tabular}{ccccccccc}
\hline$n$ & $L$ (weeks) & $k$ & $Q_{r}$ & $Q_{d}$ & $D_{r}$ & $D_{d}$ & $\nabla_{D}$ & $\nabla_{S}$ \\
\hline 1 & 4 & 5.59 & 1060.79 & 166.22 & 490 & 456 & 822403.97 & 782565.65 \\
$\mathbf{2}$ & $\mathbf{4}$ & $\mathbf{5 . 5 8}$ & $\mathbf{1 0 5 8 . 2 1}$ & $\mathbf{1 6 6 . 2 2}$ & $\mathbf{4 9 0}$ & $\mathbf{4 5 6}$ & $\mathbf{8 2 2 5 0 8 . 5 9}$ & $\mathbf{7 8 2 6 7 0 . 2 8}$ \\
3 & 4 & 5.59 & 1055.66 & 166.22 & 490 & 456 & 822490.54 & 782652.22 \\
\hline
\end{tabular}

TABle 8: Analysis of profit for customer shifting.

\begin{tabular}{lccccccc}
\hline & $D_{r}$ & $D_{d}$ & $Q_{r}$ & $Q_{d}$ & $k$ & $\nabla_{D}$ & $\nabla_{S}$ \\
\hline$\delta_{1}>\delta_{2}$ & 496.8 & 418.6 & 1067.09 & 159.91 & 5.66 & 830690.65 & 793604.35 \\
$\delta_{1}<\delta_{2}$ & 454.3 & 462.8 & 1026.95 & 167.32 & 5.21 & 804701.27 & 766334.07 \\
\hline
\end{tabular}

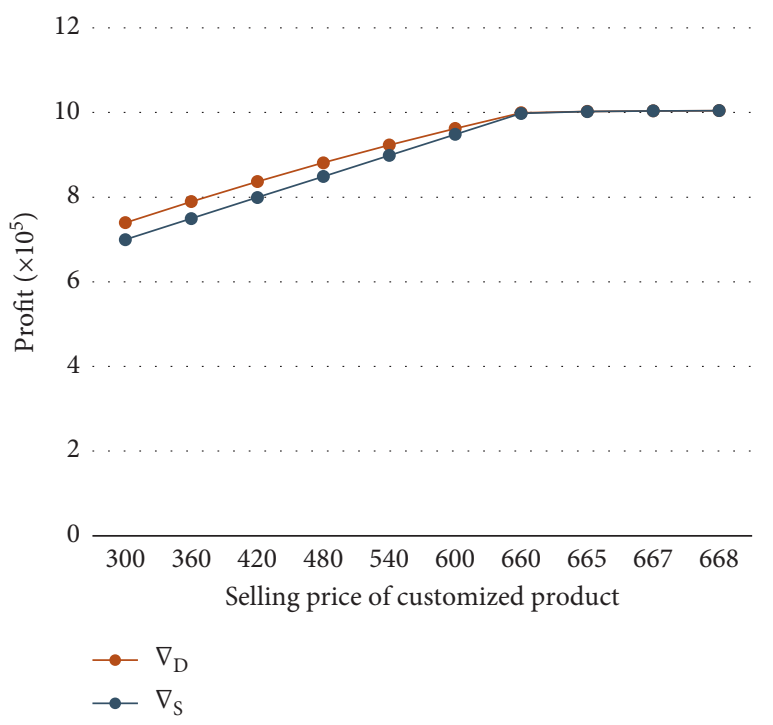

Figure 5: Managerial decisions for $\left|\sum_{i=1}^{N} C_{d i}-C_{P}\right|>20$ (Case 1). 


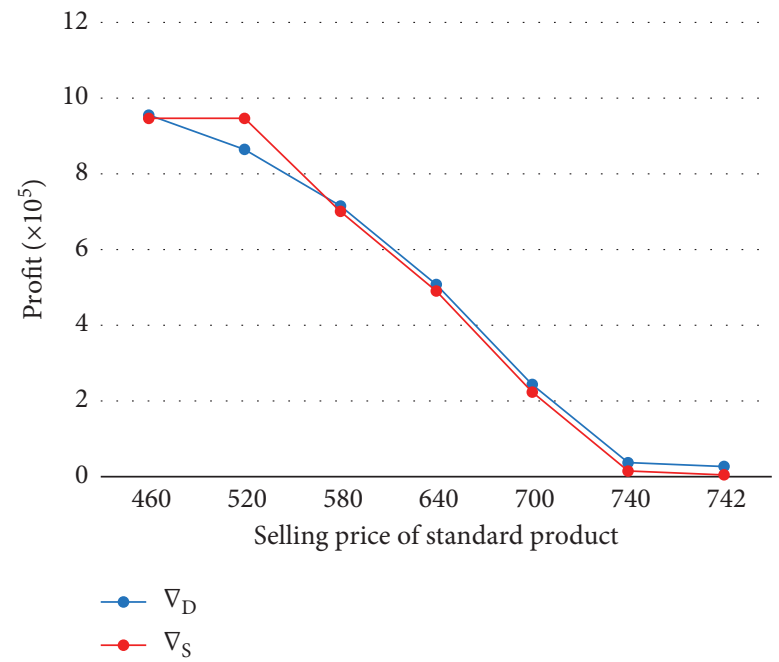

Figure 6: Managerial decisions for $\left|\sum_{i=1}^{N} C_{d i}-C_{P}\right|>20$ (Case 2).

TABle 9: Managerial decisions for $\left|\sum_{i=1}^{N} C_{d i}-C_{p}\right|<20$ (Case 1).

\begin{tabular}{lccccccccc}
\hline Sr. no. & $C_{p}$ & $C_{d}$ & $C_{p}-C_{d}$ & $D_{r}$ & $D_{d}$ & $Q_{r}$ & $Q_{d}$ & $\nabla_{D}$ \\
\hline 1 & 380 & 400 & -20 & 515.5 & 456 & 1084.15 & 166.22 & 816481.1 & 776642.8 \\
2 & 385 & 400 & -15 & 509.13 & 456 & 1078.37 & 166.22 & 818399.5 & 778561.2 \\
3 & 390 & 400 & -10 & 502.75 & 456 & 1072.60 & 166.22 & 820026.1 & 780187.8 \\
4 & 395 & 400 & -5 & 496.38 & 456 & 1066.70 & 166.22 & 821360.9 & 781522.6 \\
5 & 400 & 400 & 0 & 490.00 & 456 & 1060.80 & 166.22 & 821446.4 & 782565.7 \\
6 & 405 & 400 & 5 & 483.63 & 456 & 1054.90 & 166.22 & 823155.3 & 783317 \\
7 & 410 & 400 & 10 & 477.25 & 456 & 1048.9 & 166.22 & 823614.9 & 783776.6 \\
8 & 415 & 400 & 15 & 470.88 & 456 & 1042.8 & 166.22 & 823658.9 & 783944.4 \\
9 & 420 & 400 & 20 & 464.50 & 456 & 1036.8 & 166.22 & 823782.7 & 783820.7 \\
\hline
\end{tabular}

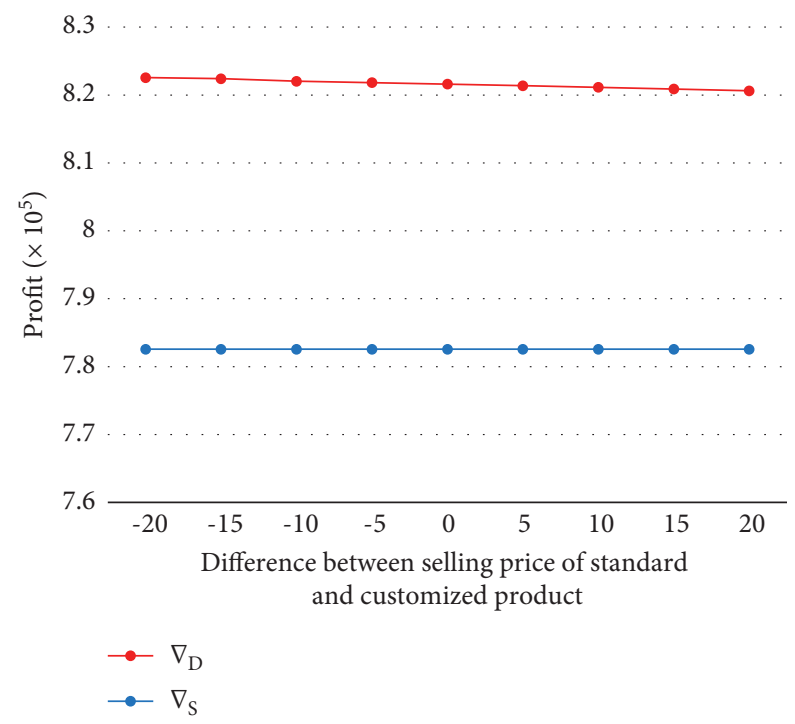

Figure 7: Managerial decisions for $\left|\sum_{i=1}^{N} C_{d i}-C_{P}\right|<20$ (Case 1).

and ultimately dual-channel behaves like single-channel only. Furthermore, Table 6 and Figure 6 present that if the selling price of the standard product increases, the difference between the selling prices of the standard and customized product also increases. As a result, firm slowly moves towards the loss because it leads to increase in price of customized product as it requires standard product for customization. 
TAвLe 10: Managerial decisions for $\left|\sum_{i=1}^{N} C_{d i}-C_{p}\right|<20$ (Case 2).

\begin{tabular}{lccccccccc}
\hline Sr. no. & $C_{p}$ & $C_{d}$ & $C_{d}-C_{p}$ & $D_{r}$ & $D_{d}$ & $Q_{r}$ & $Q_{d}$ & $\nabla_{D}$ \\
\hline 1 & 400 & 380 & -20 & 490 & 483.2 & 1060.8 & 170.59 & 822558 & 782565.7 \\
2 & 400 & 385 & -15 & 490 & 476.4 & 1060.8 & 169.51 & 822407.5 & 782565.7 \\
3 & 400 & 390 & -10 & 490 & 469 & 1060.8 & 168.40 & 822029.9 & 782565.7 \\
4 & 400 & 395 & -5 & 490 & 462.8 & 1060.8 & 167.30 & 821823.7 & 782565.7 \\
5 & 400 & 400 & 0 & 490 & 456 & 1060.8 & 166.22 & 821606.0 & 782565.7 \\
6 & 400 & 405 & 5 & 490 & 449 & 1060.8 & 165.1 & 821376.6 & 782565.7 \\
7 & 400 & 410 & 10 & 490 & 442.4 & 1060.8 & 163.9 & 821135.7 & 782565.7 \\
8 & 400 & 415 & 15 & 490 & 435.6 & 1060.8 & 162.8 & 820883.2 & 782565.7 \\
9 & 400 & 420 & 20 & 490 & 428.8 & 1060.8 & 161.7 & 820619.1 & 782565.7 \\
\hline
\end{tabular}

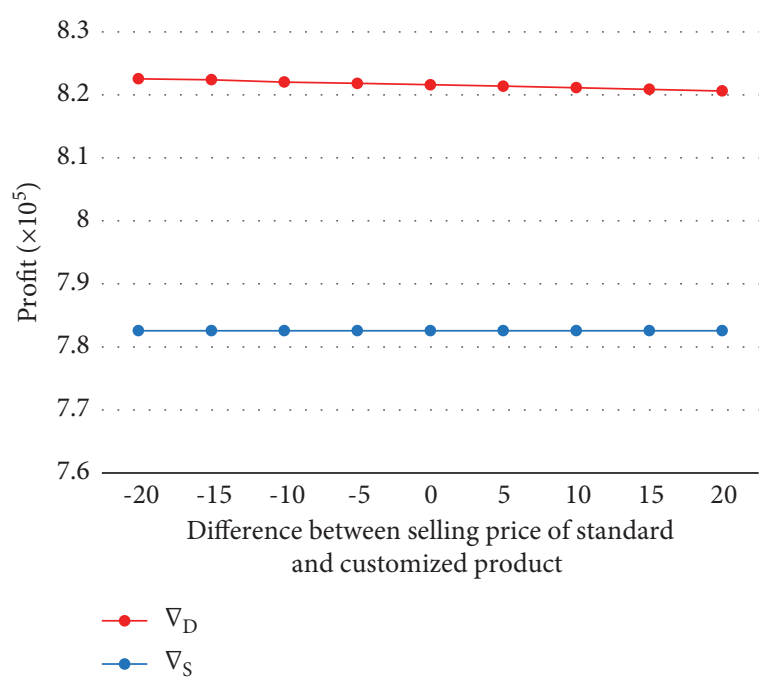

FIgURE 8: Managerial decisions for $\left|\sum_{i=1}^{N} C_{d i}-C_{P}\right|<20$ (Case 2).

Table 9 and Figure 7 characterize that though the selling price of the customized product increases, if the difference between the selling prices of standard and customized product is less than preassigned threshold value, then shifting of customers is inconspicuous. Furthermore, Table 10 and Figure 8 reflect that if the selling price of the standard product increases, but if the difference between the selling price of standard and customized product is less than preassigned threshold value, then shifting of customers is unspectacular.

Figure 9 draws the analysis of profit with markup price for both dual-channel $\left(\nabla_{D}\right)$ and single-channel $\left(\nabla_{S}\right)$ when selling price of the standard product is more than customized product. Moreover, Figure 10 draws analysis of profit with markup price for both dual-channel $\left(\nabla_{D}\right)$ and single-channel $\left(\nabla_{S}\right)$ when selling price of the standard product is less than customized product. It is observed that in both the figures, profit increases with the increase in markup margin.

\subsection{Sensitivity Analysis}

5.5.1. Sensitivity Analysis of Offline Channel. As similar to the sensitivity analysis of the online channel, the cost parameters are differed by $-10 \%,-5 \%,+5 \%$, and $+10 \%$ to sift

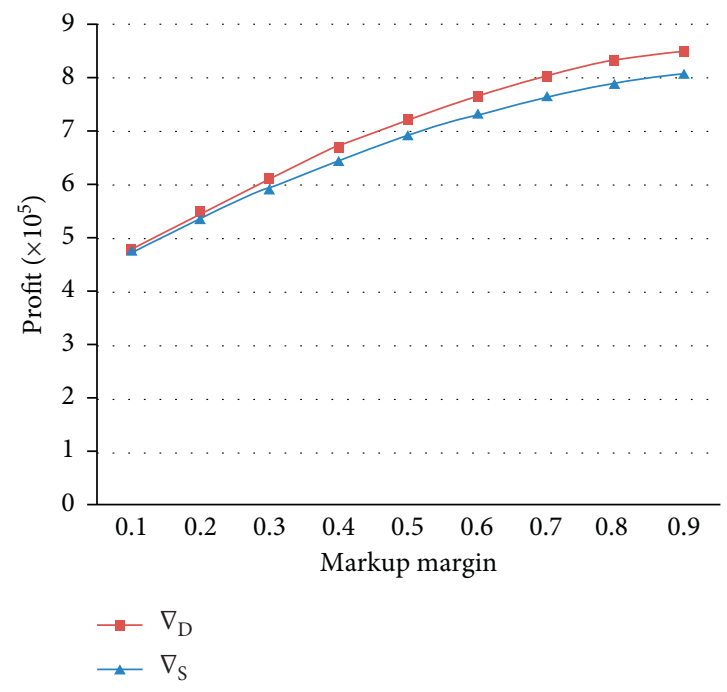

FIgURE 9: Analysis of profit with markup price when $C_{p}>\sum C_{d i}$.

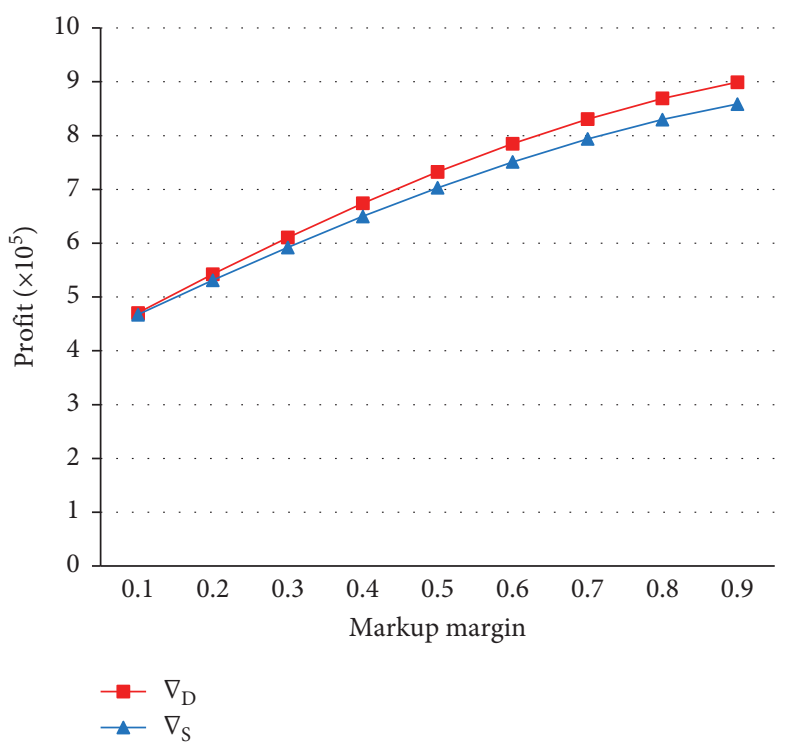

FIgURE 10: Analysis of profit with markup price when $C_{p}<\sum C_{d i}$.

the profit of the firm. Each parameter is changed one at a time while keeping the other parameters fixed. The effects of this change of the key parameters are illustrated in Table 11 
TABLE 11: Sensitivity analysis for different key parameters.

\begin{tabular}{|c|c|c|c|}
\hline Parameters & Change (in \%) & Sensitivity (offline channel) & Sensitivity (online channel) \\
\hline \multirow{4}{*}{$C_{d 1}$} & -10 & - & +1.91 \\
\hline & -5 & - & +0.97 \\
\hline & +5 & - & -1.01 \\
\hline & +10 & - & -2.05 \\
\hline \multirow{4}{*}{$C_{d 2}$} & -10 & - & +1.91 \\
\hline & -5 & - & +0.99 \\
\hline & +5 & - & -1.06 \\
\hline & +10 & - & -2.19 \\
\hline \multirow{4}{*}{$C_{d 3}$} & -10 & - & +0.26 \\
\hline & -5 & - & +0.22 \\
\hline & +5 & - & -0.22 \\
\hline & +10 & - & -0.26 \\
\hline \multirow{4}{*}{$C_{p}$} & -10 & +3.39 & - \\
\hline & -5 & +1.57 & - \\
\hline & +5 & -1.33 & - \\
\hline & +10 & -3.41 & - \\
\hline \multirow{4}{*}{$S_{r}$} & -10 & +0.02 & - \\
\hline & -5 & +0.01 & - \\
\hline & +5 & -0.01 & - \\
\hline & +10 & -0.02 & - \\
\hline \multirow{4}{*}{$C_{v}$} & -10 & +0.63 & - \\
\hline & -5 & +0.31 & - \\
\hline & +5 & -0.31 & - \\
\hline & +10 & -0.63 & - \\
\hline \multirow{4}{*}{$C_{b}$} & -10 & +0.77 & - \\
\hline & -5 & +0.39 & - \\
\hline & +5 & -0.38 & - \\
\hline & +10 & -0.77 & - \\
\hline \multirow{4}{*}{$S_{d}$} & -10 & - & +0.65 \\
\hline & -5 & - & +0.32 \\
\hline & +5 & - & -0.31 \\
\hline & +10 & - & -0.61 \\
\hline
\end{tabular}

and Figure 11. Variations of key parameters $C_{p}, S_{r}, C_{v}$, and $C_{b}$ are considered. The outcomes of this experiment are discussed as follows:

(1) The manufacturer's cost component is more sensitive than the retailer's cost component.

(2) Selling price of the standard product is the most sensitive cost, whereas that of setup cost of the retailer is the least sensitive.

5.5.2. Sensitivity Analysis of Online Channel. The cost parameters are varied over $-10 \%,-5 \%,+5 \%$, and $+10 \%$ to examine the effect of expected profit of the online channel. Each parameter is changed one at a time while keeping the other parameters fixed. The effects of this change of the key parameters are illustrated in Table 11 and Figure 12.

Variations of key parameters are $C_{d 1}, C_{d 2}, C_{d 3}$ (since only three customization's are considered), and $S_{d}$ considered. For the sake of simplicity, only three types of customizations are considered. Scrutinizing the sensitivity analysis, following points are observed:
(1) Cost components of the standard product are more sensitive than cost components of customized product.

(2) The manufacturer's cost components of standard product are more sensitive than the manufacturer's setup cost.

(3) Out of the three customizations, third customization $\operatorname{cost} C_{d 3}$ for customized product is the least sensitive.

\section{Managerial Implications}

This article provides a dual-channel supply chain model with a single manufacturer and single retailer. Managerial decisions shall be more realistic if more than one decision variables are considered instead of a single variable or any constant entity. More pragmatic managerial decisions can be obtained if multiple decision variables are assumed. Thus, decisions are made on the basis of many variable quantities such as selling price of standard product, selling price of customized product, profit of single channel and profit of dual channel, and lead time. The managerial implications of this study are enlisted as follows: 


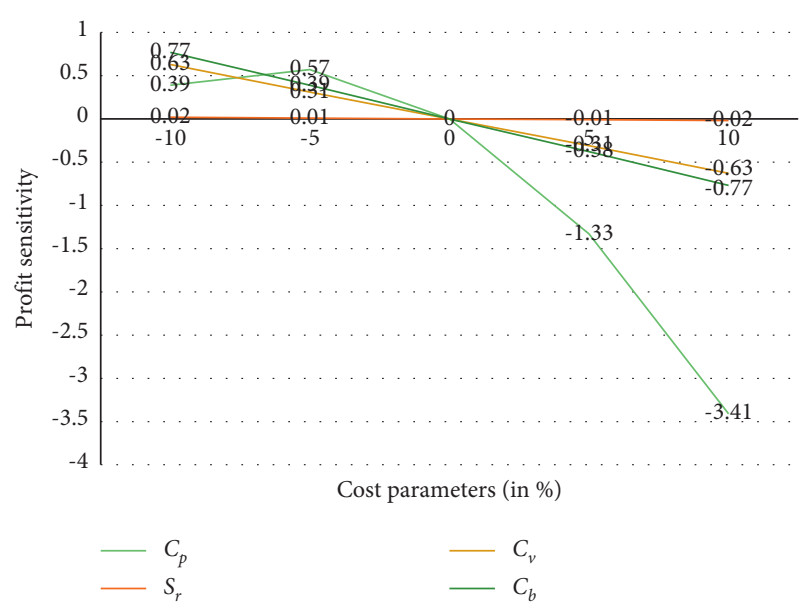

FIGURE 11: Sensitivity analysis for different key parameters in case of offline channel.

Providing the customization facility to the customers influences hike in demand which may increase the total profitability of the industry. In 1985, Dell took up this strategy, i.e., make-to-order of computers on demand of customers, and this provided Dell a sale of $\$ 70$ million in that year, and after five years of adopting the strategy, their revenue climbed to $\$ 500$ million. By the end of 2000, Dell's revenues had topped with an astounding of $\$ 25$ billion [1].

The manager can increase the overall profit of the firm if the dual-channel supply chain strategy is applied instead of the single-channel supply chain model. As a result of this strategy, the Dell's revenue was able to reach to $\$ 25$ billion within two decades [1].

A centralized dual-channel supply chain model should bring forth increased profit to the firm due to the exchange of information between the manufacturer and retailer.

The manager can reduce lead time and enhance customer service by incurring a lead time crashing cost.

An improved managerial decision can be obtained by assuming a preassigned threshold limit and unequal shifting of customers from one channel to another.

Since the manager is providing customized product in addition to standard product so price of the customized feature should be arranged in such a way that overall cost of the customized product should not increase threshold limit, otherwise customers will shift back to standard product.

The manager should not increase the selling price of the standard product beyond a limit; otherwise, the profit firm will slowly doom. On account of the fact that customization is implemented on the standard product and if the prices of the standard product increase automatically, it will lead to an increase in the price of customized product.

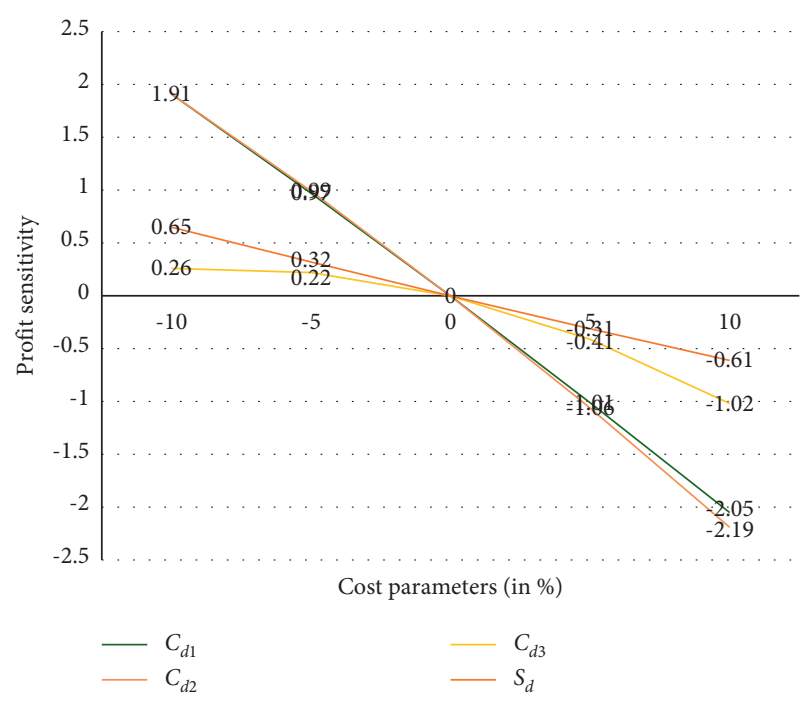

FIGURE 12: Sensitivity analysis for different key parameters in case of online channel.

\section{Conclusions}

The most important and original contribution of this study is the modifications incorporated on the existing customization strategy with the inclusion of a fixed and specified threshold limit and unequal shifting of customers from one channel to another which leads to an improved realistic scenario of dualchannel supply channel management. Moreover, due to the speculative fluctuation of demand, estimation becomes difficult task for the decision makers. Some factors such as selling price lead to a variation in demand along with uncertainty. Therefore, the decision makers should consider the probabilistic uncertainty with the sensitivity of various factors such as selling price in demand expression.

The study concluded that implementing the dual-channel supply chain policy, the company receives the personally customized demands of the customers along with standard product which increases the trust of the customers on firm. Moreover, if the firm adopts the centralized policy in that case, it can manage the complete profit parameters that are related to product after studying the market which helped in increasing the overall profit of the firm. This paper clearly depicted that if the selling price of standard product is extravagant when compared to customized product, then the firm slowly moves towards losses, whereas if the selling price of customized product is overpriced in comparison to standard product, then the dual-channel supply chain model behaves like the single-channel model. As a result, customers start preferring standard product over customized product. Moreover, if the difference between the selling prices of the standard product and customized product is less than preassigned threshold value, then there is an indistinct shifting of customers. This paper also revealed that the selling price of standard product is the most sensitive cost parameter in the model. Accordingly, the least sensitive parameters are the setup costs for the manufacturer for both channels. 
The present study is limited to some aspects such as absence of multiple retailers, strategy to reduce setup and ordering costs, implementation of vendor managed inventory (VMI) or consignment policy, integrating towards a sustainable development, and many more. Therefore, there is a significant scope of extension of this study. Considering a multiretailer dual-channel supply chain system [51, 52], a fair competition among all retail channels can be shown. The centralized supply chain profit can be improved by reducing several cost components. Thus, large cost components such as setup or ordering cost may also be diminished by an efficient investment strategy [50]. The study of VMI and consignment contracts has been supervised by many researchers in recent years [37, 58]. This agreement allows manufacturers to take the ownership of its products even after shifting to the retailer's end. A VMI or consignment contract under dual-channel centralized supply chain with the modified customization policy can be an innovative research to be concerned. Furthermore, considering a humanitarian supply chain and social and environmental sustainability, the studies of Nandra et al. [59] and Nandra et al. [60] are one of the virtuous ways of extension of this study.

\section{Appendix}

\section{A. Derivation of the Selling Price of Standard Product}

$$
\begin{aligned}
\text { Markup } & =\frac{\text { selling price }(\text { for retailer })-\text { cost price }(\text { for retailer })}{\text { cost price }(\text { for retailer })}, \\
m & =\frac{P-C_{r}}{C_{r}}, \\
m C_{r}+C_{r} & =P=C_{r}(1+m)=C_{r}(1+m)^{2}, \\
P & =C_{p}(1+m)^{2} .
\end{aligned}
$$

\section{B. Proof of Proposition 1}

$$
\begin{aligned}
& E(M-R)^{+}=\frac{|M-R|+(M-R)}{2}, \\
& E(M-R)^{+} \leq \frac{\sqrt{E(M-R)^{2}}+E(M-R)}{2} .
\end{aligned}
$$

Consider $M=D \sqrt{L}+X$ summation of variability and randomness:

$$
E(M-R)^{+} \leq \frac{\sqrt{E\left(D \sqrt{L}+E(X-R)^{2}\right.}+E(D \sqrt{L}+X-R)}{2},
$$

where $R=D L+k \sigma \sqrt{L}$ is a safety factor:

$$
E(M-R)^{+} \leq \frac{\sqrt{E(D L+X-D L+k \sigma \sqrt{L})^{2}}+E(D L+X-D L+k \sigma \sqrt{L})}{2} .
$$

In this case, we consider worst possible distribution of random variable $D_{r}$ with mean $D L$ and standard deviation $\sigma \sqrt{L}$. We get

$$
\begin{aligned}
E(M-R)^{+} & =\frac{\sqrt{E(X+k \sigma \sqrt{L})^{2}}+E((X+k \sigma \sqrt{L}))}{2} \\
& =\frac{\sqrt{E\left(X^{2}+k^{2} \sigma^{2} L+2 X k \sigma \sqrt{L}\right)}+E(X+k \sigma \sqrt{L})}{2} \\
& =\left[\frac{\sqrt{\sigma^{2} L+\left(D_{r} L\right)^{2}+k^{2} \sigma^{2} L-2 D_{r} L k \sigma \sqrt{L}}+\left(D_{r} L-k \sigma \sqrt{L}\right)}{2}\right] .
\end{aligned}
$$




\section{Proof of Proposition 2}

where

The Hessian matrix $H$ for dual-channel supply chain is as follows:

$$
H_{1}=\left[\begin{array}{ccc}
\frac{\partial^{2} \nabla_{D}}{\partial Q_{r}^{2}} & \frac{\partial^{2} \nabla_{D}}{\partial Q_{r} \partial Q_{d}} & \frac{\partial^{2} \nabla_{D}}{\partial Q_{r} \partial k} \\
\frac{\partial^{2} \nabla_{D}}{\partial Q_{d} \partial Q_{r}} & \frac{\partial^{2} \nabla_{D}}{\partial Q_{d}^{2}} & \frac{\partial^{2} \nabla_{D}}{\partial Q_{d} \partial k} \\
\frac{\partial^{2} \nabla_{D}}{\partial k \partial Q_{r}} & \frac{\partial^{2} \nabla_{D}}{\partial k \partial Q_{d}} & \frac{\partial^{2} \nabla_{D}}{\partial k^{2}}
\end{array}\right],
$$

$$
\left.\begin{array}{rl}
\frac{\partial^{2} \nabla_{D}}{\partial k^{2}} & =-\frac{\pi D_{r}}{2 Q_{r}}\left[\frac{\sigma^{4} L^{2}}{\sqrt{\sigma^{2} L+\left(D_{r} L\right)^{2}+k^{2} \sigma^{2} L-2 D_{r} L \sigma \sqrt{L}}}\right], \\
\frac{\partial^{2} \nabla_{D}}{\partial Q_{r} \partial k} & =\frac{\pi D_{r}}{2 Q_{r}^{2}}\left[\frac{k \sigma^{2} L-D_{r} L \sigma \sqrt{L}}{\sqrt{\sigma^{2} L+\left(D_{r} L\right)^{2}+k^{2} \sigma^{2} L-2 D_{r} L \sigma \sqrt{L}}}-\sigma \sqrt{L}\right], \\
\frac{\partial^{2} \nabla_{D}}{\partial Q_{d} \partial k} & =0, \\
\frac{\partial^{2} \nabla_{D}}{\partial k \partial Q_{d}} & =0, \\
\frac{\partial^{2} \nabla_{D}}{\partial Q_{r} \partial Q_{d}} & =0, \\
\frac{\partial^{2} \nabla_{D}}{\partial Q_{d}^{2}} & =-\frac{2 S_{d} D_{d}}{Q_{d}^{3}}, \\
\frac{\partial^{2} \nabla_{D}}{\partial Q_{d} \partial Q_{r}} & =0, \\
\frac{\partial^{2} \nabla_{D}}{\partial Q_{r}^{2}} & =-\frac{2}{Q_{r}^{3}}\left[\begin{array}{l}
\left.A_{r} D_{r}+\frac{S_{r} D_{r}}{n}+D_{r} C L+\pi D_{r}\left(\sqrt{\sigma^{2} L+\left(D_{r} L\right)^{2}+k^{2} \sigma^{2} L-2 D_{r} L k \sigma \sqrt{L}}\right)\right], \\
2 Q_{r}^{2}
\end{array}\right]
\end{array}\right] .
$$

The first-order principal minor of $\left|H_{1}\right|$ is

$$
\begin{aligned}
\left|H_{1,1}\right| & =\left|\frac{\partial^{2} \nabla_{D}}{\partial Q_{r}^{2}}\right|_{\left(Q_{r}^{*}, Q_{d}^{*}, k^{*}\right)} \\
& =-\frac{2}{Q_{r}^{3}}\left[A_{r} D_{r}+\frac{S_{r} D_{r}}{n}+D_{r} C L+\pi D_{r}\left(\sqrt{\sigma^{2} L+\left(D_{r} L\right)^{2}+k^{2} \sigma^{2} L-2 D_{r} L k \sigma \sqrt{L}}\right)\right]<0 .
\end{aligned}
$$


The second-order principal minor of $\left|H_{1}\right|$ is

$$
\begin{aligned}
\left|\left(H_{1}\right)_{2,2}\right|_{\left(Q_{r}^{*}, Q_{d}^{*}, k^{*}\right)} & =\left(\frac{\partial^{2} \nabla_{D}}{\partial Q_{r}^{2}}\right)\left(\frac{\partial^{2} \nabla_{D}}{\partial Q_{d}^{2}}\right) \\
& =\left(-\frac{2}{Q_{r}^{3}}\left[A_{r} D_{r}+\frac{S_{r} D_{r}}{n}+D_{r} C L+\pi D_{r}\left(\sqrt{\sigma^{2} L+\left(D_{r} L\right)^{2}+k^{2} \sigma^{2} L-2 D_{r} L k \sigma \sqrt{L}}\right)\right]\right)\left(-\frac{2 S_{d} D_{d}}{Q_{d}^{3}}\right)>0 .
\end{aligned}
$$

The third-order principal minor of $\left|\left(H_{1}\right)_{3,3}\right|_{\left(Q_{r}^{*}, Q_{d}^{*}, k^{*}\right)}$ is

$$
\begin{aligned}
& \left|\left(H_{1}\right)_{3,3}\right|_{\left(Q_{r}^{*}, Q_{d}^{*}, k^{*}\right)}=\frac{\partial^{2} \nabla_{D}}{\partial Q_{d}^{2}}\left[\left(\frac{\partial^{2} \nabla_{S}}{\partial Q_{r}^{2}}\right)\left(\frac{\partial^{2} \nabla_{S}}{\partial k^{2}}\right)-\left(\frac{\partial^{2} \nabla_{S}}{\partial k \partial Q_{r}}\right)^{2}\right] \\
& =\left[\frac{2 S_{d} D_{d}}{Q_{d}^{3}}\right] \frac{\pi D_{r}^{2}}{Q_{r}^{4}}\left(A_{r}+\frac{S_{r}}{n}+C L\right) \frac{\sigma^{4} L^{2}}{\sqrt{\sigma^{2} L+\left(D_{r} L\right)^{2}+k^{2} \sigma^{2} L-2 D_{r} L \sigma \sqrt{L}}} \\
& +\pi \sigma^{4} L^{2}+\frac{\pi k \sigma^{3} L \sqrt{L}}{2 \sqrt{\sigma^{2} L+\left(D_{r} L\right)^{2}+k^{2} \sigma^{2} L-2 D_{r} L \sigma \sqrt{L}}}-\frac{D_{r} L^{2} \sigma^{2}}{2 \sqrt{\sigma^{2} L+\left(D_{r} L\right)^{2}+k^{2} \sigma^{2} L-2 D_{r} L \sigma \sqrt{L}}} \\
& -\frac{\pi\left(2 k^{2} \sigma^{4} L^{2}+\sigma^{4} L^{2}+2 D_{r}^{2} L^{3} \sigma^{2}-4 D_{r} \sigma^{3} L^{2} \sqrt{L}\right)}{4\left(\sigma^{2} L+\left(D_{r} L\right)^{2}+k^{2} \sigma^{2} L-2 D_{r} L \sigma \sqrt{L}\right)}>0 \\
& \Longrightarrow\left(A_{r}+\frac{S_{r}}{n}+C L\right) \frac{\sigma^{4} L^{2}}{\sqrt{\sigma^{2} L+\left(D_{r} L\right)^{2}+k^{2} \sigma^{2} L-2 D_{r} L \sigma \sqrt{L}}} \\
& +\pi \sigma^{4} L^{2}+\frac{\pi k \sigma^{3} L \sqrt{L}}{2 \sqrt{\sigma^{2} L+\left(D_{r} L\right)^{2}+k^{2} \sigma^{2} L-2 D_{r} L \sigma \sqrt{L}}}>\frac{D_{r} L^{2} \sigma^{2}}{2 \sqrt{\sigma^{2} L+\left(D_{r} L\right)^{2}+k^{2} \sigma^{2} L-2 D_{r} L \sigma \sqrt{L}}} \\
& +\frac{\pi\left(2 k^{2} \sigma^{4} L^{2}+\sigma^{4} L^{2}+2 D_{r}^{2} L^{3} \sigma^{2}-4 D_{r} \sigma^{3} L^{2} \sqrt{L}\right)}{4\left(\sigma^{2} L+\left(D_{r} L\right)^{2}+k^{2} \sigma^{2} L-2 D_{r} L \sigma \sqrt{L}\right)} \\
& \Longrightarrow\left(A_{r}+\frac{S_{r}}{n}+C L\right) \frac{\sigma^{4} L^{2}}{\sqrt{\sigma^{2} L+\left(D_{r} L\right)^{2}+k^{2} \sigma^{2} L-2 D_{r} L \sigma \sqrt{L}}} \\
& +\pi \sigma^{4} L^{2}+\frac{\pi k \sigma^{3} L \sqrt{L}}{2 \sqrt{\sigma^{2} L+\left(D_{r} L\right)^{2}+k^{2} \sigma^{2} L-2 D_{r} L \sigma \sqrt{L}}}+\frac{D_{r} \sigma^{3} L^{2} \sqrt{L}}{\sigma^{2} L+\left(D_{r} L\right)^{2}+k^{2} \sigma^{2} L-2 D_{r} L \sigma \sqrt{L}} \\
& >\frac{D_{r} L^{2} \sigma^{2}}{2 \sqrt{\sigma^{2} L+\left(D_{r} L\right)^{2}+k^{2} \sigma^{2} L-2 D_{r} L \sigma \sqrt{L}}}+\frac{\pi\left(2 k^{2} \sigma^{4} L^{2}+\sigma^{4} L^{2}+2 D_{r}^{2} L^{3} \sigma^{2}\right)}{4\left(\sigma^{2} L+\left(D_{r} L\right)^{2}+k^{2} \sigma^{2} L-2 D_{r} L \sigma \sqrt{L}\right)} .
\end{aligned}
$$


We see that all the principal minors of the Hessian matrix are negative. Hence, the Hessian matrix $H_{1}$ is negative definite at $\left(Q_{r}^{*}, Q_{d}^{*}, k^{*}\right)$. Therefore, the total expected dual-channel profit function attains its global maximum at $\left(Q_{r}^{*}, Q_{d}^{*}, k^{*}\right)$.

\section{Proof of Corollary 1}

The Hessian matrix $H$ for single-channel supply chain is as

$$
H_{2}=\left[\begin{array}{cc}
\frac{\partial^{2} \nabla_{D}}{\partial Q_{r}^{2}} & \frac{\partial^{2} \nabla_{S}}{\partial Q_{r} \partial k} \\
\frac{\partial^{2} \nabla_{S}}{\partial k \partial Q_{r}} & \frac{\partial^{2} \nabla_{S}}{\partial k^{2}}
\end{array}\right],
$$

follows:

$$
\begin{aligned}
\frac{\partial^{2} \nabla_{S}}{\partial Q_{r}^{2}} & =-\frac{2}{Q_{r}^{3}}\left[A_{r} D_{r}+\frac{S_{r} D_{r}}{n}+D_{r} C L+\pi D_{r}\left(\sqrt{\sigma^{2} L+\left(D_{r} L\right)^{2}+k^{2} \sigma^{2} L-2 D_{r} L k \sigma \sqrt{L}}\right)\right], \\
\frac{\partial^{2} \nabla_{S}}{\partial k \partial Q_{r}} & =\frac{\pi D_{r}}{2 Q_{r}^{2}}\left[\frac{k \sigma^{2} L-D_{r} L \sigma \sqrt{L}}{\sqrt{\sigma^{2} L+\left(D_{r} L\right)^{2}+k^{2} \sigma^{2} L-2 D_{r} L k \sigma \sqrt{L}}}-\sigma \sqrt{L}\right], \\
\frac{\partial^{2} \nabla_{S}}{\partial k^{2}} & =-\frac{\pi D_{r}}{2 Q_{r}}\left[\frac{\sigma^{4} L^{2}}{\sqrt{\sigma^{2} L+\left(D_{r} L\right)^{2}+k^{2} \sigma^{2} L-2 D_{r} L \sigma \sqrt{L}}}\right], \\
\frac{\partial^{2} \nabla_{S}}{\partial Q_{r} \partial k} & =\frac{\pi D_{r}}{2 Q_{r}^{2}}\left[\frac{k \sigma^{2} L-D_{r} L \sigma \sqrt{L}}{\sqrt{\sigma^{2} L+\left(D_{r} L\right)^{2}+k^{2} \sigma^{2} L-2 D_{r} L \sigma \sqrt{L}}}-\sigma \sqrt{L}\right] .
\end{aligned}
$$

The first-order principal minor of $\left|H_{2}\right|$ is

$$
\begin{aligned}
\left|H_{1,1}\right|\left(Q_{r}^{*}, k^{*}\right) & =\left|\frac{\partial^{2} \nabla_{S}}{\partial Q_{r}^{2}}\right|_{\left(Q_{r}^{*}, k^{*}\right)} \\
& =-\frac{2}{Q_{r}^{3}}\left[A_{r} D_{r}+\frac{S_{r} D_{r}}{n}+D_{r} C L+\pi D_{r}\left(\sqrt{\sigma^{2} L+\left(D_{r} L\right)^{2}+k^{2} \sigma^{2} L-2 D_{r} L k \sigma \sqrt{L}}\right)\right]<0 .
\end{aligned}
$$

The second-order principal minor of $\left|H_{2}\right|$ is

$$
\begin{aligned}
\left|H_{2,2}\right|_{\left(Q_{r}^{*}, k^{*}\right)}= & \left(\frac{\partial^{2} \nabla_{S}}{\partial Q_{r}^{2}}\right)\left(\frac{\partial^{2} \nabla_{S}}{\partial k^{2}}\right)-\left(\frac{\partial^{2} \nabla_{S}}{\partial k \partial Q_{r}}\right)^{2} \\
= & \left(-\frac{2}{Q_{r}^{3}}\left[A_{r} D_{r}+\frac{S_{r} D_{r}}{n}+D_{r} C L+\pi D_{r}\left(\sqrt{\sigma^{2} L+\left(D_{r} L\right)^{2}+k^{2} \sigma^{2} L-2 D_{r} L k \sigma \sqrt{L}}\right)\right]\right) \\
& \cdot\left(-\frac{\pi D_{r}}{2 Q_{r}}\left[\frac{\sigma^{4} L^{2}}{\sqrt{\sigma^{2} L+\left(D_{r} L\right)^{2}+k^{2} \sigma^{2} L-2 D_{r} L \sigma \sqrt{L}}}\right]\right) \\
& -\left(\frac{\pi D_{r}}{2 Q_{r}^{2}}\left[\frac{k \sigma^{2} L-D_{r} L \sigma \sqrt{L}}{\sqrt{\sigma^{2} L+\left(D_{r} L\right)^{2}+k^{2} \sigma^{2} L-2 D_{r} L \sigma \sqrt{L}}}-\sigma \sqrt{L}\right]\right)^{2}
\end{aligned}
$$




$$
\begin{aligned}
= & \frac{\pi D_{r}^{2}}{Q_{r}^{4}}\left(A_{r}+\frac{S_{r}}{n}+C L\right) \frac{\sigma^{4} L^{2}}{\sqrt{\sigma^{2} L+\left(D_{r} L\right)^{2}+k^{2} \sigma^{2} L-2 D_{r} L \sigma \sqrt{L}}} \\
& +\pi \sigma^{4} L^{2}+\frac{\pi k \sigma^{3} L \sqrt{L}}{2 \sqrt{\sigma^{2} L+\left(D_{r} L\right)^{2}+k^{2} \sigma^{2} L-2 D_{r} L \sigma \sqrt{L}}}-\frac{D_{r} L^{2} \sigma^{2}}{2 \sqrt{\sigma^{2} L+\left(D_{r} L\right)^{2}+k^{2} \sigma^{2} L-2 D_{r} L \sigma \sqrt{L}}} \\
& -\frac{\pi\left(2 k^{2} \sigma^{4} L^{2}+\sigma^{4} L^{2}+2 D_{r}^{2} L^{3} \sigma^{2}-4 D_{r} \sigma^{3} L^{2} \sqrt{L}\right)}{4\left(\sigma^{2} L+\left(D_{r} L\right)^{2}+k^{2} \sigma^{2} L-2 D_{r} L \sigma \sqrt{L}\right)}>0, \\
\Longrightarrow & \left(A_{r}+\frac{S_{r}}{n}+C L\right) \frac{\sigma^{4} L^{2}}{\sqrt{\sigma^{2} L+\left(D_{r} L\right)^{2}+k^{2} \sigma^{2} L-2 D_{r} L \sigma \sqrt{L}}} \\
& +\pi \sigma^{4} L^{2}+\frac{\pi k \sigma^{3} L \sqrt{L}}{2 \sqrt{\sigma^{2} L+\left(D_{r} L\right)^{2}+k^{2} \sigma^{2} L-2 D_{r} L \sigma \sqrt{L}}}>\frac{D_{r} L^{2} \sigma^{2}}{2 \sqrt{\sigma^{2} L+\left(D_{r} L\right)^{2}+k^{2} \sigma^{2} L-2 D_{r} L \sigma \sqrt{L}}} \\
& +\frac{\pi\left(2 k^{2} \sigma^{4} L^{2}+\sigma^{4} L^{2}+2 D_{r}^{2} L^{3} \sigma^{2}-4 D_{r} \sigma^{3} L^{2} \sqrt{L}\right)}{4\left(\sigma^{2} L+\left(D_{r} L\right)^{2}+k^{2} \sigma^{2} L-2 D_{r} L \sigma \sqrt{L}\right)}, \\
\Longrightarrow & \left(A_{r}+\frac{S_{r}}{n}+C L\right) \frac{\sigma^{4} L^{2}}{\sqrt{\sigma^{2} L+\left(D_{r} L\right)^{2}+k^{2} \sigma^{2} L-2 D_{r} L \sigma \sqrt{L}}} \\
& +\pi \sigma^{4} L^{2}+\frac{\pi k \sigma^{3} L \sqrt{L}}{2 \sqrt{\sigma^{2} L+\left(D_{r} L\right)^{2}+k^{2} \sigma^{2} L-2 D_{r} L \sigma \sqrt{L}}}+\frac{\pi\left(2 k^{2} \sigma^{4} L^{2}+\sigma^{4} L^{2}+2 D_{r}^{2} L^{3} \sigma^{2}\right)}{D_{r}^{2} L^{2} \sigma^{2}} \\
& >\frac{D_{r} \sigma^{3} L^{2} \sqrt{L}}{2 \sqrt{\sigma^{2} L+\left(D_{r} L\right)^{2}+k^{2} \sigma^{2} L-2 D_{r} L \sigma \sqrt{L}}}+\frac{\pi\left(\sigma^{2} L+\left(D_{r} L\right)^{2}+k^{2} \sigma^{2} L-2 D_{r} L \sigma \sqrt{L}\right)}{4 k^{2} \sigma^{2} L-2 D_{r} L \sqrt{L}}
\end{aligned}
$$

We see that all the principal minors of the Hessian matrix are negative. Hence, the Hessian matrix $H_{1}$ is negative definite at $\left(Q_{r}^{*}, k^{*}\right)$. Therefore, the total expected single-channel profit function attains its global maximum at $\left(Q_{r}^{*}, k^{*}\right)$.

\section{Data Availability}

The data used to support the findings of this paper are freely accessible through the Internet and cited articles.

\section{Conflicts of Interest}

The authors declare that they have no conflicts of interest.

\section{References}

[1] MaRS, "Case study: dell-distribution and supply chain innovation," MaRS Startup Toolkit: Canada's Innovation Community, Ottawa, Canada, 2021, https://learn.marsdd. com/article/case-study-dell-distribution-and-supply-chaininnovation/.

[2] A. Tsay and N. Agrawal, "Channel conflict and coordination in the e-commerce age," Production and Operations Management, vol. 13, no. 1, pp. 93-110, 2004.

[3] T. Zhang and T. M. Choi, "Optimal consumer sales tax policies for online-offline retail operations with consumer returns," Naval Research Logistics, vol. 68, no. 6, pp. 701-720, 2020.

[4] C. Wilder, HP's Online Push, Information Week, San Francisco, CA, USA, 1999.
[5] A. Barman, R. Das, and P. Kanti De, "Optimal pricing and greening decision in a manufacturer retailer dual-channel supply chain," Materials Today: Proceedings, vol. 42, no. 2, pp. 870-875, 2021.

[6] K. Takahashi, T. Aoi, D. Hirotani, and K. Morikawa, "Inventory control in a twoechelon dual-channel supply chain with setup of production and delivery," International Journal of Production Economics, vol. 133, no. 2, pp. 403-415, 2011.

[7] S.-M. Hosseini-Motlagh, M. Nouri-Harzvili, T.-M. Choi, and S. Ebrahimi, "Reverse supply chain systems optimization with dual channel and demand disruptions: sustainability, CSR investment and pricing coordination," Information Sciences, vol. 503, pp. 606-634, 2019.

[8] P. He, Y. He, and H. Xu, "Buy-online-and-deliver-from-store strategy for a dual-channel supply chain considering retailer's location advantage," Transportation Research Part E, vol. 144, Article ID 102127, 2020.

[9] D. Littler and D. Melanthiou, "Consumer perceptions of risk and uncertainty and the implications for behaviour towards innovative retail services: the case of internet banking," Journal of Retailing and Consumer Services, vol. 13, no. 6, pp. 431-443, 2006.

[10] M. Bhattacharyya and S. S. Sana, "A mathematical model on eco-friendly manufacturing system under probabilistic demand," RAIRO-Operations Research, vol. 53, no. 5, pp. 1899-1913, 2019.

[11] N. M. Modak, N. Modak, S. Panda, and S. S. Sana, "Analyzing structure of two-echelon closed-loop supply chain for pricing, quality and recycling management," Journal of Cleaner Production, vol. 171, pp. 512-528, 2018.

[12] R. Yan and Z. Pei, "Retail services and firm profit in a dualchannel market," Journal of Retailing and Consumer Services, vol. 16, no. 4, pp. 306-314, 2009. 
[13] J. Zhou, R. Zhao, and B. Wang, "Behavior-based price discrimination in a dual-channel supply chain with retailer's information disclosure," Electronic Commerce Research and Applications, vol. 39, Article ID 100916, 2019.

[14] C. Jing, Z. Hui, and S. Ying, "Implementing coordination contracts in a manufacturer stackelberg dual-channel supply chain," Omega, vol. 40, no. 1, pp. 571-583, 2012.

[15] S. Huang, C. Yang, and H. Liu, "Pricing and production decisions in a dual-channel supply chain when production costs are disrupted," Economic Modelling, vol. 30, pp. 521-538, 2013.

[16] S. Huang, C. Yang, and X. Zhang, "Pricing and production decisions in dual-channel supply chains with demand disruptions," Computers \& Industrial Engineering, vol. 62, no. 1, pp. 70-80, 2012.

[17] B. Dan, G. Xu, and C. Liu, "Pricing policies in a dual-channel supply chain with retail services," International Journal of Production Economics, vol. 139, no. 1, pp. 312-320, 2012.

[18] S. S. Sana, "A structural mathematical model on two echelon supply chain syatem," Annals of operations Research, 2021.

[19] P. Zhang, Y. He, and C. Shi, "Retailer's channel structure choice: online channel, offline channel, or dual channels?" International Journal of Production Economics, vol. 191, pp. 37-50, 2017.

[20] S. K. Mukhopadhyay, X. Zhu, and X. Yue, "Optimal contract design for mixed channels under information asymmetry," Production and Operations Management, vol. 17, no. 6, pp. 641-650, 2008.

[21] W.-y. K. Chiang, D. Chhajed, and J. D. Hess, "Direct marketing, indirect profits: a strategic analysis of dual-channel supply-chain design," Management Science, vol. 49, no. 1, pp. 1-20, 2003.

[22] S. S. Sana, "A structural mathematical model on two echelon supply chain system," Annals of Operations Research, 2021.

[23] S.-M. Hosseini-Motlagh, M. Johari, S. Ebrahimi, and P. Rogetzer, "Competitive channels coordination in a closedloop supply chain based on energy-saving effort and cost-tariff contract," Computers \& Industrial Engineering, vol. 490, Article ID 106763, 2020.

[24] M. G. Dekimpe, K. Gielens, J. Raju, and J. S. Thomas, "Strategic assortment decisions in information-intensive and turbulent environments," Journal of Retailing, vol. 87, no. 1, pp. S17-S28, 2011.

[25] S. S. Sana, "Price competition between green and non green products under corporate social responsible firm," Journal of Retailing and Consumer Services, vol. 55, Article ID 102118, 2020.

[26] K. Rana, S. R. Singh, S. R. Singh, N. Saxena, and S. S. Sana, "Growing items inventory model for carbon emission under the permissible delay in payment with partially backlogging," Green Finance, vol. 3, no. 2, pp. 153-174, 2021.

[27] F. Salvador, P. M. De Holan, and F. T. Piller, "Cracking the code of mass customization," MIT Sloan Management Review, vol. 50, pp. 71-78, 2009.

[28] M. Comstock, K. Johansen, and M. Winroth, "From mass production to mass customization: enabling perspectives from the Swedish mobile telephone industry," Production Planning \& Control, vol. 15, no. 4, pp. 362-372, 2004.

[29] B. G. C. Dellaert and S. Stremersch, "Marketing mass-customized products: striking a balance between utility and complexity," Journal of Marketing Research, vol. 42, no. 2, pp. 219-227, 2005.

[30] H. Ismail, I. Reid, J. Mooney, J. Poolton, and I. Arokiam, "How small and medium enterprises effectively participate in the mass customization game," IEEE Transactions on Engineering Management, vol. 54, no. 1, pp. 86-97, 2007.

[31] M. J. Rungtusanatham and F. Salvador, "From mass production to mass customization: hindrance factors, structural inertia, and transition hazard," Production and Operations Management, vol. 17, no. 3, pp. 385-396, 2008.

[32] K. Matsui, "Optimal bargaining timing of a wholesale price for a manufacturer with a retailer in a dual-channel supply chain," European Journal of Operational Research, vol. 287, no. 1, pp. 225-236, 2020.

[33] P. Zhang, Y. He, and X. Zhao, "Preorder-online, pickup-instore" strategy for a dual-channel retailer," Transportation Research Part E: Logistics and Transportation Review, vol. 122, pp. 27-47, 2019.

[34] K. Y. Chen, M. Kaya, and Ö. Özer, "Dual sales channel management with service competition," Manufacturing \& Service Operations Management, vol. 10, no. 4, pp. 676-691, 2008.

[35] G. Hua, S. Wang, and T. C. E. Cheng, "Price and lead time decisions in dual-channel supply chains," European Journal of Operational Research, vol. 205, no. 1, pp. 113-126, 2010.

[36] G. Li, F. Huang, T. C. E. Cheng, and P. Ji, "Competition between manufacturer's online customization channel and conventional retailer," IEEE Transactions on Engineering Management, vol. 62, no. 2, pp. 150-157, 2015.

[37] R. Batarfi, M. Y. Jaber, and S. Zanoni, "Dual-channel supply chain: a strategy to maximize profit," Applied Mathematical Modelling, vol. 40, no. 21-22, pp. 9454-9473, 2016.

[38] Y. He, H. Huang, and D. Li, "Inventory and pricing decisions for a dual-channel supply chain with deteriorating products," Operational Research, vol. 20, no. 3, pp. 1461-1503, 2018.

[39] W.-Y. Kevin Chiang and G. E. Monahan, "Managing inventories in a two-echelon dual-channel supply chain," European Journal of Operational Research, vol. 162, no. 2, pp. 325-341, 2005.

[40] D.-Q. Yao, X. Yue, X. Wang, and J. J. Liu, “The impact of information sharing on a returns policy with the addition of a direct channel," International Journal of Production Economics, vol. 97, no. 2, pp. 196-209, 2005.

[41] N. M. Modak and P. Kelle, "Managing a dual-channel supply chain under price and delivery-time dependent stochastic demand," European Journal of Operational Research, vol. 272, no. 1, pp. 147-161, 2018.

[42] A. Dumrongsiri, M. Fan, A. Jain, and K. Moinzadeh, "A supply chain model with direct and retail channels," European Journal of Operational Research, vol. 187, no. 3, pp. 691-718, 2008.

[43] P. He, Y. He, and H. Xu, "Channel structure and pricing in a dual-channel closed-loop supply chain with government subsidy," International Journal of Production Economics, vol. 213, pp. 108-123, 2018.

[44] A. Roy, S. S. Sana, and K. Chaudhuri, "Joint decision on EOQ and pricing strategy of a dual channel of mixed retail and e-tail comprising of single manufacturer and retailer under stochastic demand," Computers \& Industrial Engineering, vol. 102, pp. 423-434, 2016.

[45] I. Moon, D. K. Yoo, and S. Saha, "The distribution-free newsboy problem with multiple discounts and upgrades," Mathematical Problems in Engineering, vol. 2016, Article ID 2017253, 11 pages, 2016.

[46] H. Scarf, "A min-max solution of an inventory problem," in Studies in The Mathematical Theory of Inventory and Production, K. Arrow, S. Karlin, and H. Scarf, Eds., pp. 201-209, Stanford University Press, Palo Alto, CA, USA, 1958. 
[47] H. Xu, Z. Z. Liu, and S. H. Zhang, "A strategic analysis of dualchannel supply chain design with price and delivery lead time considerations," International Journal of Production Economics, vol. 139, no. 2, pp. 654-663, 2012.

[48] J. Q. Yang, X. M. Zhang, H. Y. Fu, and C. Liu, "Inventory competition in a dual-channel supply chain with delivery lead time consideration," Applied Mathematical Modelling, vol. 42, pp. 675-692, 2017.

[49] X. Yue and J. Liu, "Demand forecast sharing in a dual-channel supply chain," European Journal of Operational Research, vol. 174, no. 1, pp. 646-667, 2006.

[50] A. Majumder, R. Guchhait, and B. Sarkar, "Manufacturing quality improvement and setup cost reduction in a vendorbuyer supply chain model," European Journal of Industrial Engineering, vol. 11, no. 5, pp. 588-612, 2017.

[51] A. Majumder, C. K. Jaggi, and B. Sarkar, "A multi-retailer supply chain model with backorder and variable production cost," RAIRO-Operations Research, vol. 52, no. 3, pp. 943-954, 2018.

[52] B. Sarkar, C. Zhang, A. Majumder, M. Sarkar, and Y. W. Seo, "A distribution free newsvendor model with consignment policy and retailer's royalty reduction," International Journal of Production Research, vol. 56, no. 15, pp. 1-20, 2018.

[53] P. Zhang, Y. Xiong, and Z. Xiong, "Coordination of a dualchannel supply chain after demand or production cost disruptions," International Journal of Production Research, vol. 53, no. 10, pp. 3141-3160, 2015.

[54] J. S. Raju and A. Roy, "Market information and firm performance," Management Science, vol. 46, no. 8, pp. 1075-1084, 2000.

[55] W. Huang and J. M. Swaminathan, "Introduction of a second channel: implications for pricing and profits," European Journal of Operational Research, vol. 194, no. 1, pp. 258-279, 2009.

[56] G. Gallego and I. Moon, "The distribution free newsboy problem: review and extensions," Journal of the Operational Research Society, vol. 44, no. 8, pp. 825-834, 1993.

[57] N. C. Petruzzi and M. Dada, "Pricing and the newsvendor problem: a review with extensions," Operations Research, vol. 47, no. 2, pp. 183-194, 1999.

[58] B. Sarkar, A. Majumder, M. Sarkar, N. Kim, and M. Ullah, "Effects of variable production rate on quality of products in a single-vendor multi-buyer supply chain management," The International Journal of Advanced Manufacturing Technology, vol. 99, no. 1-4, pp. 567-581, 2018.

[59] R. Nandra, A. Majumder, and M. Mishra, "A multi-retailer sustainable supply chain model with coordination and quality deterioration," RAIRO-Operational Research, vol. 55, pp. S2773-S2794, 2020.

[60] K. R. Marak, R. Nandra, B. K. Dey, A. Majumder, and R. Kaur, "Establishing relation between production rate and product quality in a single-vendor multi-buyer supply chain model," International Journal of Services Operations and Informatics, vol. 11, no. 2/3, p. 1, 2021. 